\title{
Inflammatory activation after experimental cardiac tamponade and the effects of complement C5a inhibition
}

Andrea Vass M.D.

Ph.D. Thesis

Institute of Surgical Research

Second Department of Medicine

University of Szeged, Hungary

2013 


\title{
Inflammatory activation after experimental cardiac tamponade and the effects of complement C5a inhibition
}

\author{
Andrea Vass M.D.
}

Ph.D. Thesis

\author{
Institute of Surgical Research \\ Second Department of Medicine \\ University of Szeged, Hungary
}

Doctoral School of Multidisciplinary Medical Science

Physiology, Pathophysiology and Pharmacology of the Cardiovascular System (Educational Programme)

Experimental Study of Clinically Significant Cardiorespiratory

Pathomechanisms (Research Programme)

Supervisor:

József Kaszaki Ph.D. 


\section{List of full papers related to the subject of the thesis}

1. Vass A, Süveges G, Érces D, Nógrády M, Varga G, Földesi I, Futakuchi M, Imai M, Okada N, Okada H, Boros M, Kaszaki J: Inflammatory activation after experimental cardiac tamponade. Eur Surg Res 51:1-13, 2013.DOI: 10.1159/000352089 IF 0.75

2. Érces D, Nógrády M, Nagy E, Varga G, Vass A, Süveges G, Imai M, Okada N, Okada H, Boros M, Kaszaki J: Complement c5a antagonist treatment improves the acute circulatory and inflammatory consequences of experimental cardiac tamponade. Crit Care Med 41: 2013. (accepted for publication) DOI: 10.1097/CCM.0b013e31828a6768 IF 6.123

\section{Publication indirectly related to the thesis}

1. Molnár G, Csonka E, Vass A, Boros M, Kaszaki J: Circulatory consequences of reduced endogenous nitric oxide production during small-volume resuscitation. Acta Physiol Hung 98: 393-408, 2011.

IF 0.84

\section{Other publications}

1. Nemes A, Forster T, Ungi I, Nagy V, Vass A, Pálinkás A, Varga A, Csanády M. The coronary flow velocity reserve measured by stress transoesophageal echocardiography evaluates the success of coronary interventions--results of a 5-year follow-up. Scand Cardiovasc J. 39: 286-292, 2005.

IF:0.757

2. Rosztóczy A, Vass A, Izbéki F, Kurucsai G, Róka R, Horváth T, Lonovics J, Forster T, Wittmann T: Savas gastrooesophagealis reflux által provokált coronariaspazmus kórképe. Magy Belorv Arch. 61: 203-206, 2006.

IF: 0

3. Rosztóczy A, Vass A, Izbéki F, Nemes A, Rudas L, Csanády M, Lonovics J, Forster T, Wittmann T: The evaluation of gastro-oesophageal reflux and oesophagocardiac reflex in patients with angina-like chest pain following cardiologic investigations. Int J Cardiol. 118: 62-68, 2007.

IF: 1.765

4. Csanády M, Tóth F, Hogye M, Vass A, Sepp R, Csanády M Jr, Czigner J, Kiss JG, Jóri J, Forster T. Hearing disturbances in hypertrophic cardiomyopathy. Is the sensorineural disorder neurogenic or myogenic? Int J Cardiol. 116: 53-56, 2007.

IF: 1.765 


\section{CONTENTS}

List of papers 3

List of abbreviations $\quad 5$

$\begin{array}{ll}\text { Summary } & 6\end{array}$

1. Introduction $\quad 7$

$\begin{array}{lll}\text { 1.1. Circulatory shock } & 7\end{array}$

$\begin{array}{lll}\text { 1.2. Determinants of cardiac pump function } & 7\end{array}$

1.3. Analysis of cardiac function 9

1.4. Cardiac tamponade and its circulatory effects 11

1.5. A possible therapeutic route: the complement system 13

$\begin{array}{ll}2 . & 13\end{array}$

3. Materials and Methods 16

3.1. Instrumentation of animals in Studies I and II 16

3.2. Haemodynamic measurements in Studies I and II 17

3.3. Evaluation of intestinal microcirculation: $\mathrm{pCO}_{2}$ gap measurements 17

3.4. Biochemical measurements 17

3.5. Experimental protocols $\quad 19$

$\begin{array}{lll}3.6 & \text { Statistical analysis } & 20\end{array}$

4. Results 21

4.1. Study I - Haemodynamic and inflammatory responses after cardiac tamponade 21

4.1.1. Changes in haemodynamics 21

4.1.2. Changes in biochemical parameters 26

4.2. Study II - Cardiac effects of complement C5a antagonist treatment 29

4.2.1. Changes in cardiac and pulmonary haemodynamics 29

4.2.2. Changes in biochemical parameters 34

5. Discussion 37

5.1. $\quad$ Study I $\quad 37$

5.2. Study II 40

6. Summary of new findings 43

7. References 44

8. Acknowledgements 50

9. Annex 51 


\section{List of abbreviations}

AcPepA acetyl-peptide-A (complement C5a antagonist)

big-ET big endothelin

$\mathrm{CO} \quad$ cardiac output

CVP central venous pressure

ET-1 endothelin-1

EVLWI extravascular lung water index

GEDV global end-diastolic volume

GEF global ejection fraction

HMGB1 high-mobility group box protein-1

HR heart rate

IHC immunohistochemistry

LHEDV left heart end-diastolic volume

LV left ventricular

MAP mean arterial pressure

MPO myeloperoxidase

NO nitric oxide

$\mathrm{NO}_{\mathrm{x}} \quad$ nitrite/nitrate

PAP pulmonary arterial pressure

PiCCO pulse contour cardiac output

PMN polymorphonuclear neutrophil

PRSW preload recruitable stroke work

PVRI pulmonary vascular resistance index

RHEDV right heart end-diastolic volume

RV right ventricular

SMA superior mesenteric artery

SV stroke volume

SVRI systemic vascular resistance index

TNF- $\alpha$ tumour necrosis factor-alpha 


\section{SUMMARY}

Cardiogenic shock is common in patients with cardiac or extra-cardiac filling disorders. Cardiac tamponade is a life-threatening medical emergency situation where the pump failure is caused by effusions of blood, pus or fluids. Drainage of the pericardial sac through pericardiocentesis or surgical pericardiotomy is the first choice of treatment, but supportive medical therapy should be considered following or parallel to the relief of the intrapericardial pressure, with a view to avoiding low flow-induced peripheral complications. Moreover, it is recognized that splanchnic macro- and microcirculatory dysfunctions are linked to local and systemic inflammatory activation, and the increased afterload may subsequently worsen the hypoperfusion of the peripheral organs and result in an increased oxygen demand of the myocardium. The general purpose of the research reported in the dissertation was to characterize the major components of the pro-inflammatory profile of the post-tamponade phase, in association with the changes in overall haemodynamics, and to outline a possible therapeutic route to reverse the cardiac tamponade-caused detrimental consequences in a clinically relevant large animal model. We considered that a better understanding of the elements of these mechanisms may lead to new prospects for interventions designed to dampen or reverse the secondary detrimental consequences of cardiac failures.

In Study I, we hypothesized that acute failure of the myocardial pump function is accompanied by significant inflammatory activation, which can play important roles in further gastrointestinal complications. We investigated the immediate effects of cardiac tamponade on the systemic and peripheral circulations and characterized the major components of the pro-inflammatory profile of the post-tamponade phase, in association with the changes in overall haemodynamics. We identified characteristic macrohaemodynamic changes, together with apparent signs of a splanchnic inflammatory reaction after relief of the tamponade. The evidence further suggests that the activation of the complement and endothelin systems may be significant components of the inflammatory cascade that is activated in porcine pericardial tamponade. It iscurrently widely accepted that inflammatory activation plays a decisive role in low-flow conditions, although the potential of 'anti-inflammatory' compounds to prevent or cure hypoperfusion-induced in vivo processes is very limited. With this background, we hypothesized that early inhibition of complement C5a might well reduce the adverse cardiac and inflammatory consequences after relief of the cardiac tamponade. In Study II, during the acute phase of cardiac tamponade in our clinically relevant large animal model we used a synthetic, antisense, 17 amino acid peptide acetylated at the N-terminal alanine (acetylpeptide-A - AcPepA). Previous studies have shown that this compound is capable of binding directly to $\mathrm{C} 5 \mathrm{a}$ peptide. We hypothesized that, through this mechanism, AcPepA can influence the early cardiac and inflammatory changes, and the results furnished evidence that the administration of AcPepA significantly limits the extent of the cardiac dysfunction in this scenario. 


\section{INTRODUCTION}

\subsection{Circulatory shock}

Maintenance of adequate perfusion of vital organs is critical for survival. Shock may be defined as a state in which profound and widespread reduction of tissue perfusion leads to reversible, and then, if prolonged, irreversible cellular injury. Since a reduction of tissue perfusion is a central issue, it is important to consider the factors that control this vital function. Organ perfusion is dependent on an appropriate perfusion pressure, which in turn is determined by two variables, the cardiac output $(\mathrm{CO})$ and the systemic vascular resistance (SVR). The second critical determinant of arterial pressure, the CO, is the product of stroke volume (SV) and heart rate (HR).

The classification of shock is usually based on the aetiology. Cardiogenic shock, extracardiac obstructive shock, hypovolaemic shock and distributive shock are major categories (Parrillo 1991). The final pathway leads to cell death, but some characteristics of shock are the same regardless of the underlying cause or pathogenesis. One common denominator of different forms of shock is a low CO. Patients with shock develop a severe decrease in $\mathrm{CO}$ and hence a low perfusion of vital organs. The survival depends on the correct early diagnosis and therapy.

Two basic mechanisms can lead to a decrease of $\mathrm{CO}$ in shock: a failure of preload (i.e. a diminished venous return) in consequence of a decreased blood volume (in hypovolaemic shock) or a decrease in the efficiency of the pump function of the heart. The latter occurs in cardiogenic shock, in which the primary failure is myocardial rather than peripheral. This can arise after acute myocardial infarction or as a result of pericardial tamponade. In pericardial tamponade, compression of the atria and the right ventricle causes an acute rise in the pericardial pressure (by the accumulation of blood in the pericardial sac), which hinders the diastolic filling of the heart (Tyson et al. 1984), thereby leading to a decreased CO.

\subsection{Determinants of cardiac pump function}

The myocardial performance is dependent on the preload, afterload, (HR) and contractility, and is influenced by neurohormonal and local endothelial cell-derived factors. The cardiac pump function or performance depends on many parameters, which act in parallel, and normally exist to some degree. Examples of performance parameters include the $\mathrm{CO}$, left ventricular (LV) SV, the rate of fibre shortening, the stroke work, the myocardial compliance and the ejection fraction. 
1. The preload is a result of heterometric autoregulation. When the cardiac muscle is stretched, it tends to develop greater contractile tension on excitation (this is Starling's law of the heart). Thus, the SV tends to increase in proportion to the preload (diastolic filling).

2. The afterload is determined by the total peripheral vascular resistance (TPVR). A sudden rise in afterload causes an immediate decrease in ejection fraction and a rise in end-systolic volume (ESV). The compensation can occur in two ways. An increased ESV coupled with a normal venous return leads to an elevated preload, and the SV is maintained by Starling's law. In addition, contractility may increase secondary to an increased coronary perfusion pressure, the Gregg effect (Anrep and Saalfeld 1933, Gregg 1963). Thus, small changes in afterload have a minimal steady-state effect on performance as measured via the SV or CO, despite a significant initial effect.

3. $H R$ increases are usually associated with small increases in contractile force. However, an increased HR is associated with a proportionally shorter diastolic filling time and for this reason the atrial contraction becomes far more important at high HR. It has been established that the heart contractility depends on increasing HR in most mammals. The ventricular myocardium has an inherent ability to increase its strength of contraction, independently of neurohormonal control, in response to an increase in contraction. In humans, this myocardial property causes the contractile force to rise, as the contraction frequency is increased from 60 to about 180-200 beats $\min ^{-1}$, and then to decline with further increase in frequency (the force-frequency relation) .

4. Contractility is often defined as the intrinsic ability of a cardiac muscle fibre to contract at a given fibre length. Changes in the ability to produce force during contraction result from different degrees of binding between myosin and actin filaments. The degree of binding that occurs depends on the concentration of $\mathrm{Ca}^{2+}$ in the cell. The cytosolic $\mathrm{Ca}^{2+}$ level is the determinant of the involved myocardial fibre number in the contraction process and the maximum velocity of myocardial fibre shortening. An increased contractility, positive inotropic effect is reflected in a higher myocardial fibre shortening velocity with a higher cytosolic $\mathrm{Ca}^{2+}$ concentration in systole: more troponin is activated from higher levels of $\mathrm{Ca}^{2+}$ with more actin-myosin cross-bridges in unit time, and ultimately the myocardial fibre contraction is more extensive and faster. The performance improves at any given preload and afterload.

Neural influences mean that the sympathetic discharge to the ventricles increases their contractility. Likewise, circulating epinephrine increases contractility. Other inotropic agents, such as $\mathrm{Ca}^{2+}$ sensitizers, phosphodiesterase inhibitors, cardiac glycosides, catecholamines and 
endothelial cell-derived factors, also modify the myocardial contractility and/or $\mathrm{Ca}^{2+}$ availability.

\subsection{Analysis of cardiac function}

Examinations of cardiac contractility in clinical practice would be extremely beneficial, but at present direct measurement is not possible. In experimental practice, there few invasive techniques are available with which to evaluate or calculate this parameter. The end-systolic pressure-volume or pressure-diameter relationship is a fundamental description of systolic cardiac mechanics, with especial regard to the preload recruitable stroke work (PRSW) relationship. PRSW is another index of contractility, which is perhaps less influenced by other parameters. Each pressure-volume/diameter loop is derived by caval vein occlusion. The slope of the derived linear relationship is a measure of contractility independent of the preload and afterload (Molnár et al. 2011).

In clinical practice, non-invasive measurements of LV dimensions, volumes, ejection fraction and other indices of the systolic and diastolic function can be carried out by ultrasound techniques. Transthoracic echocardiography has an important and established diagnostic role and has been used successfully to monitor segmental wall motion, ejection fraction, valvular function, and to measure cardiac cavities. The evaluation of the ejection fraction is important for risk stratification before any surgical intervention. However, the ejection fraction is influenced by preload and afterload alterations without any change in contractility. Depending on the loading conditions, hearts with a lower ejection fraction can produce a greater $\mathrm{CO}$. Although roughly indicative of the cardiac reserve, the ejection fraction is an inconsistent marker of the overall cardiac function preoperatively.

Assessment of the LV function includes linear measurements, such as the LV internal dimension in diastole and systole, from which parameters such as fractional shortening could be derived. Two-dimensional echocardiography allows area measurements and derived volume calculations (i.e. Simpson rule measurements). Once the systolic and diastolic volumes have been determined, the SV can be calculated. The forward $\mathrm{CO}$ then equals the product of HR and SV. Assuming the absence of a mitral or aortic insufficiency, this can represent the CO. The application of Doppler echocardiography provides information on systolic flow parameters, and more recently the diastolic function. Doppler techniques have several advantages: they are non-invasive and simple, and provide continuous data.. In contrast, they also have some important limitations, such as the relative inaccuracy (high inter/intraobserver variability) of the cross-sectional measurements in the LV outflow tract. 
With the help of some sophisticated new methods, such as strain rate imaging, the ventricular function can be determined exactly, but from a practical point of view it is rather complicated. Another new method is automated endocardial border definition, used for automatic quantification of the instantaneous LV volume. The SV and ejection fraction can be calculated from the maximum and minimum volumes. A further refinement of this method in combination with the instantaneous determination of systolic pressure is that it can provide load-independent information regarding ventricular contractility through the creation of a pressure-volume loop (Gorcsan et al. 1994), although its routine use during the operation and subsequently in the intensive care unit is limited.

There are two prevalent invasive techniques in clinical practice, for the measurement and calculation of the preload and CO parameters by a thermodilution method. One of these techniques, which applies the pulmonary artery (Swan-Ganz) catheter, has been used for over 20 years. Pulmonary artery thermodilution and the subsequent clinically established transcardiopulmonary thermodilution technique allow the measurement not only of the $\mathrm{CO}$, but also of several other parameters reflecting the right (RV) and the biventricular function. Pulmonary artery thermodilution permits the measurement and calculation of the RV ejection fraction, the RV stroke volume, and the RV end-diastolic volume (Trepte et al. 2011). With the development of additional facilities, and particularly the continuous measurement of $\mathrm{CO}$, the pulmonary artery catheter remains the mainstay in the bedside monitoring of myocardial performance in critically ill patients.

Another invasive technique is the Pulse Contour Cardiac Output (PiCCO) system, which uses volumetric, transcardiopulmonary thermodilution. This technique is methodologically comparable and has been described as being a reliable and less invasive method for the measurement of CO (Reuter et al. 2010). It further enables an assessment of the global ejection fraction (GEF), describing the ratio of the SV to the global end-diastolic volume (GEDV). For the calculation of GEF, the SV is multiplied by 4 on the assumption that the GEDV represents the volume of all four heart chambers (GEF $=4 \times \mathrm{SV} / \mathrm{GEDV}$ ). The main advantages of the PiCCO system are the online function and the possibility of pulse contour analysis. A combination of the pulse contour $\mathrm{CO}$ and volumetric ejection fraction monitoring system permits calculation of the right heart and left heart end-diastolic volumes (RHEDV and LHEDV) (Végh et al. 2009).

Less invasive methods for continuous and rapid perioperative monitoring are clearly needed to detect changes in central haemodynamics in order to optimize the haemodynamic performance and oxygen delivery. A promising method is an ultrasound-based technique for 
the measurement of blood flow velocity and aortic diameter simultaneously in the descending aorta, with the use of transoesophageal echocardiography with a probe containing two ultrasound transducers (Odenstedt et al. 2001).

\subsection{Cardiac tamponade and its circulatory effects}

Cardiogenic shock may occur in patients with cardiac or extracardiac filling disorders such as cardiac tamponade (Topalian et al. 2008, Bodson et al. 2011). Cardiac tamponade is a typical cause of obstructive shock. It is defined by an acute circulatory failure secondary to compression of the heart chambers by a pericardial effusion. Tamponade is a life-threatening condition that is diagnosed clinically by an elevated jugular venous pressure, hypotension and pulsus paradoxus in the setting of a pericardial effusion. The diagnosis is usually easy if shock is present, but it may be difficult if the effusion develops without obvious circulatory failure. Knowledge of the pathophysiology and the echocardiographic characteristics of this disease is therefore fundamental.

The incidence of cardiac tamponade is poorly documented. Numerous epidemiological studies have examined patients suffering from a pericardial effusion without focusing on tamponade. Interestingly, it was observed in a retrospective study of more than 10000 ambulatory patients without previous pericardial disease that the existence of a small pericardial effusion on transthoracic echocardiography was associated with an increased 1year mortality rate from $11 \%$ to $26 \%$ (Mitiku and Heidenreich, 2011).

Studies establishing the cause of pericardial effusion have yielded mixed results, probably due to the different diagnostic techniques applied. In a single centre study, 106 patients were hospitalized for a large pericardial effusion, defined by a thickness greater than or equal to $20 \mathrm{~mm}$ in diastole, with or without a syndrome of cardiac tamponade; the causes found were cancer (36\%), idiopathic (30\%), infection (21\%), myxoedema (8\%), autoimmune diseases and vasculitis (5\%). The reported incidence of acute pericardial tamponade is approximately $2 \%$ of penetrating trauma. In emergency situations, a haemopericardium is frequently encountered in patients with ascending aorta dissection or ventricular rupture following infarction. After cardiac surgery, the development of a pericardial haematoma behind the right atrium is a common cause of shock. However, its diagnosis may be difficult and requires transoesophageal echocardiography (Bodson et al. 2011). The increasing number of cardiac surgical interventions has resulted in a subsequent elevation in the overall number of iatrogenic pericardial tamponades. Further potential causes of cardiac perforation include 
central line placement, pacemaker insertion, cardiac catheterization and electrophysiological ablation procedures (Valley and Fly, 2007).

A raised intrapericardial pressure can occur by three main mechanisms: increased fluid within the intrapericardial space (pericardial tamponade), an increased volume of the cardiac chambers (cardiac diseases), or an increased stiffness of the pericardium (constrictive pericarditis). In the normal situation, the pericardium has a small capacitance reserve that will accommodate only a small increase in cardiac chamber size and/or pericardial fluid volume (approximately 150-250 $\mathrm{mL}$ ) before a significant increase in the pericardial pressure (Goldstein 2004).

The acute rise in pericardial pressure compresses the atria and the right ventricle and hinders the diastolic filling of the heart (Tyson et al. 1984), thereby leading to a decreased CO. Vasoconstriction is a general compensatory reaction in forms of shock involving low $\mathrm{CO}$. It occurs as an appropriate response that serves to restore the declining arterial flow and pressure towards former values. The vasoconstriction is non-uniform, and the redistributed blood flow can maintain the blood supply for the heart and brain at a relatively normal level in the short run. The sympathetic vasoconstriction diverts the blood flow from organs with constricted arterioles to organs whose vessels constrict little under intense vasoconstriction. The resistance of the coronary circulation practically does not change, whereas the resistance of the skin, skeletal muscle and gastrointestinal circulations increases enormously (Bond and Green, 1983). This process is mediated through the activation of sympathetic nervous system and various humoral mediators (Kaszaki et al. 1989), leading to systemic vasoconstriction, tachycardia and fluid retention (Topalian et al. 2008). However, the price for the potentially beneficial effects of selective vasoconstriction is severe hypoxia in the underperfused organs (Bulkley et al. 1983, Bailey et al. 1987, Buerke et al. 2011). Moreover, the increased afterload may subsequently worsen the peripheral hypoperfusion and increase the oxygen demand of the myocardium.

Circulatory disturbances of cardiac origin fundamentally influence the perfusion of other organs, and especially the gastrointestinal tract. Gastrointestinal perfusion is often compromised early relative to other vascular beds in critical illness, major surgery or exercise due to the neurohumoral elements of circulatory redistribution. This complex response is partly mediated through the sympathetic nervous system (Chien 1967), but various humoral mediators also participate in the maintenance of vasoconstriction (catecholamines, the reninangiotensin system and endothelins). 
In cases of cardiac tamponade, drainage of the pericardial sac through pericardiocentesis or surgical pericardiotomy is the first choice for therapy (Seferovic et al. 2006), but removal of the pericardial fluid can lead to a reperfusion phenomenon with further peripheral reactions. As a consequence of hypoxia and reoxygenation, reactive oxygen radicals are generated and polymorphonuclear neutrophil (PMN) leukocytes are activated. The formation of these radicals may lead to disintegration of the cell membranes, structural damage and decreased cellular functions (Boros et al. 1989, Prasad et al. 1990). Highmobility group box protein-1 (HMGB1), released passively by necrotic and damaged cells, was recently identified as an important signal for leukocyte recruitment (Scaffidi et al. 2002). Further factors identified in the background of PMN leukocyte accumulation are an increased level of endothelin-1 (ET-1) formation and a decreased level of nitric oxide (NO) formation, which coexist in ischaemia-reperfusion syndromes (Boros 2003). ET-1, one of the most powerful endogenous vasoactive mediators, may contribute to the impairment of the microcirculation through its vasoconstrictor and pro-adhesive effects (Boros et al. 1998). Moreover, it results in histamine release from resident mast cells (Kaszaki et al. 2008), and influences the activation of the complement cascade (Soop et al. 2004).

\subsection{A possible therapeutic route: the complement system}

Complement was first discovered in the 1890s when it was found to aid or "complement" the killing of bacteria by heat-stable antibodies present in normal serum. The complement system consists of more than 30 proteins that are present either as soluble proteins in the blood or as membrane-associated proteins. This system is composed of a network of proteins that play an important role in innate and adaptive immunity, ranging from the opsonization of pathogens, through chemoattraction to the removal of apoptotic and necrotic cells. Activation of the system is exquisitely regulated, and inappropriate activation due either to deficiencies in key complement proteins or to dysregulated activation has adverse consequences (Sarma and Ward 2011). Complement activation leads to a sequential cascade of enzymatic reactions (known as complement activation pathways), resulting in the formation of the potent anaphylatoxins C3a and C5a, which elicit a plethora of physiological responses that range from chemoattraction to apoptosis. These proteins are capable of cell lysis and the principal site of synthesis is the liver. Complement activation is known to occur through three different pathways: alternative, classical and lectin (Figure 1), involving proteins that mostly exist as inactive zymogens, which are sequentially cleaved and activated. Activation of the classical complement pathway occurs via $\mathrm{C} 1, \mathrm{C} 4$ and $\mathrm{C} 2$, and activation of 
an alternative complement pathway via factor D, C3 and factor B. Both pathways lead to the activation of $\mathrm{C} 3$. The protein fragment $\mathrm{C} 3 \mathrm{~b}$, split form $\mathrm{C} 3$, is necessary for activation of the terminal complement components, C5-9. These form the membrane attack complex. When inserted into cell membranes, they cause osmotic lysis of the cell. C3a and C5a bind to receptors on mast cells and basophils, resulting in the release of histamine and other mediators of anaphylaxis.

C5a is a potent chemoattractant for PMNs and monocyte-macrophages. C5a is a 74 aminoacid peptide generated from C5 during complement activation. C5a acts efficiently as an anaphylatoxin, stimulating cells such as leukocytes and endothelial cells, and is also a potent chemotactic factor for PMNs and other inflammatory cells bearing the C5a receptor. C5a is therefore considered to be one of the most potent inflammatory mediators. Inflammatory cells respond to nanomolar concentrations of C5a with intracellular $\mathrm{Ca}^{2+}$ mobilization, stimulation of chemotaxis, aggregation, degranulation and the production of superoxide anions (Fujita et al. 2004).

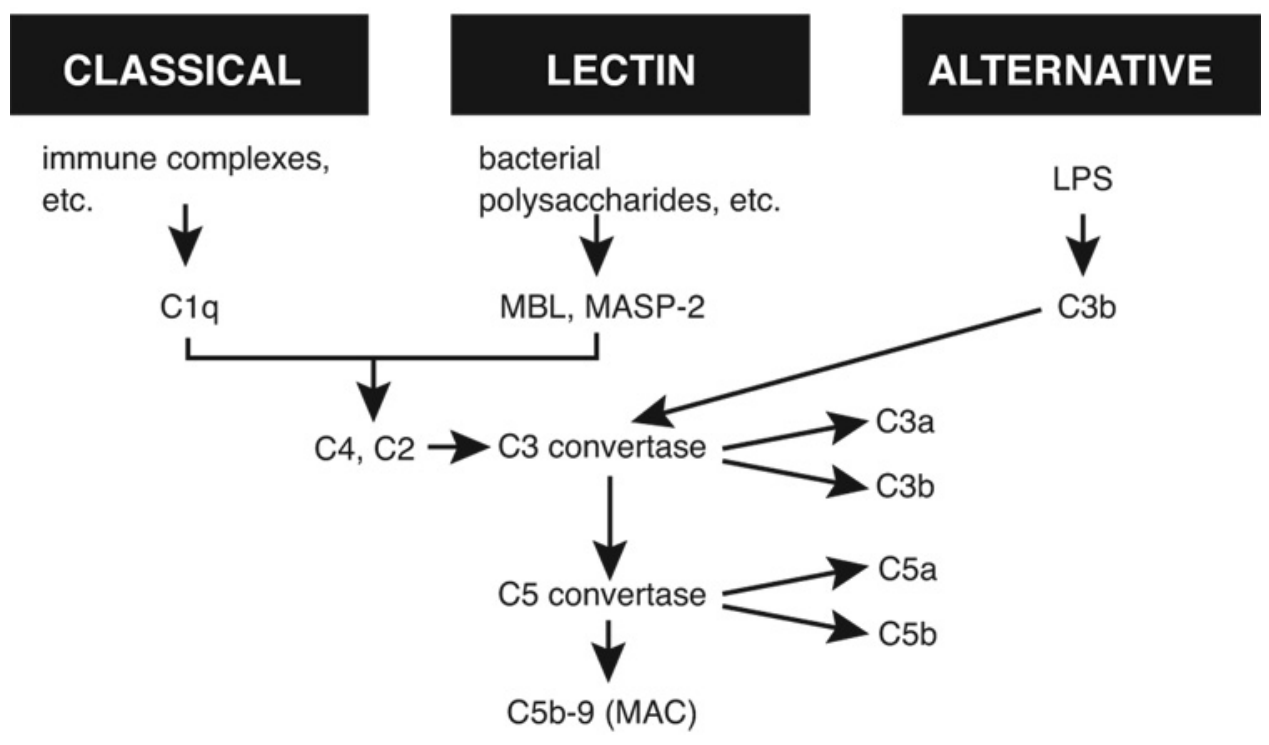

Figure 1: The three pathways of complement activation, collectively resulting in biologically active split products of C3 and C5 (abbreviations: LPS - lipopolysaccharide; MBL mannose-binding lectin; MASP-2 - MBL-associated protein-2; MAC - membrane attack complex) (Ward PA: Sepsis, apoptosis and complement. Biochem Pharmacol 2008; 76: 13831388). 


\section{MAIN GOALS}

With regard to this background, we hypothesized that acute failure of the myocardial pump function is accompanied by significant inflammatory activation, which can play an important role in the development of further clinical complications.

Our primary aim was to investigate the immediate effects of a cardiac tamponade on the central and peripheral haemodynamics, with special emphasis on the intestinal circulation. To this end, we designed a clinically relevant, large animal model with which to determine the macro- and microcirculatory changes induced by experimental cardiac tamponade. With this model, we planned to characterize the major components of the pro-inflammatory profile of the post-tamponade phase, in association with the changes in overall haemodynamics. We assumed that a better understanding of the elements of this mechanism may lead to new prospects for interventions designed to dampen or reverse the secondary, detrimental consequences of acute heart failure.

Our secondary aim was to investigate the inhibitory effects of the complement C5a antagonist acetyl-peptide-A (AcPepA), a synthetic, antisense, 17 amino acid peptide acetylated at the $\mathrm{N}$-terminal alanine, on the early circulatory and inflammatory changes in our animal model of cardiac tamponade. It is widely accepted that inflammatory activation plays a decisive role in these conditions, although the potential of 'anti-inflammatory' compounds to prevent or cure low perfusion-induced in vivo processes is very limited. With this background, we hypothesized that the early inhibition of C5a might well reduce the adverse haemodynamic and inflammatory consequences after the relief of the cardiac tamponade. 


\section{MATERIALS AND METHODS}

The experiments were carried out in strict adherence to the NIH guidelines for the use of experimental animals and the study was approved by the Ethical Committee for the Protection of Animals in Scientific Research at the University of Szeged (V./148/2013).

\subsection{Instrumentation of animals in Studies I and II}

Inbred Vietnamese minipigs of both sexes (weighing $24 \pm 3 \mathrm{~kg}$ ) were fasted for $12 \mathrm{~h}$ preoperatively, but received water ad libitum. Anaesthesia was induced with a mixture of ketamine $\left(20 \mathrm{mg} \mathrm{kg}^{-1}\right)$ and xylazine $\left(2 \mathrm{mg} \mathrm{kg}^{-1} \mathrm{im}\right)$ and maintained with a continuous infusion of propofol $\left(50 \mu \mathrm{L} \mathrm{min}{ }^{-1} \mathrm{~kg}^{-1} i v ; 6 \mathrm{mg} \mathrm{kg}^{-1} \mathrm{~h}^{-1}\right)$ supplemented with ketamine $\left(5 \mathrm{mg} \mathrm{kg}^{-1}\right)$ xylazine $\left(0.5 \mathrm{mg} \mathrm{kg}^{-1}\right)$ mixture $\mathrm{im}$ before thoracotomy and after $90 \mathrm{~min}$ of the observation period. After endotracheal intubation, the animals were mechanically ventilated with the tidal volume set at $9 \pm 2 \mathrm{~mL} \mathrm{~kg}^{-1}$, and the respiratory rate was adjusted to maintain the end-tidal pressure of $\mathrm{CO}_{2}$ and arterial $\mathrm{pCO}_{2}$ in the range 35-45 mmHg. Positive end-expiratory pressure was not applied during the cardiac tamponade.

The animals were placed in a supine position on a heating pad for maintenance of the body temperature between 36 and $37{ }^{\circ} \mathrm{C}$, and received an infusion of Ringer's lactate at a rate of $10 \mathrm{~mL} \mathrm{~kg}^{-1} \mathrm{~h}^{-1}$ during the experiments. The right jugular vein was cannulated (7 $\mathrm{F}$; Edwards Lifesciences LLC, Irvine, U.S.A.) for the measurement of central venous pressure (CVP) and for fluid administration. The right femoral artery and vein were dissected and a thermodilution catheter (PULSION Medical Systems SE, Munich, Germany) was placed in the femoral artery for the measurement of mean arterial pressure (MAP) and CO by a transpulmonary thermodilution method (PiCCO; PULSION Medical Systems SE, Munich, Germany). A pulmonary artery catheter (PV2057 VoLEF Catheter; PULSION Medical Systems SE, Munich, Germany) was inserted via the right femoral vein into the pulmonary artery by tracing the pressure signals.

After a midline abdominal incision, the root of the superior mesenteric artery (SMA) was dissected free. An ultrasonic flow probe (Transonic Systems Inc., Ithaca, NY, U.S.A.) was placed around the exposed SMA to measure the mesenteric blood flow.

Left lateral thoracotomy was performed and a cannula was fixed into the pericardial cavity in all groups. In all protocols, the animals were monitored continuously and a period of 30 min was allowed for recovery from surgery. At the end of the experiments, small intestinal tissue biopsies were taken for biochemical and immunohistochemical analysis and the animals were killed with an overdose of sodium pentobarbital. 


\subsection{Haemodynamic measurements in Studies I and II}

CVP and blood flow signals were monitored continuously and registered with a computerized data-acquisition system (SPELL Haemosys; Experimetria Ltd., Budapest, Hungary). For further haemodynamic monitoring, we used a combination of PiCCO Plus V 5.2.2 and VoLEF V 1.0 (PULSION Medical Systems SE, Munich, Germany) monitors (Végh et al. 2009). The MAP, CO, HR, GEDV and extravascular lung water index (EVLWI) were measured with the PICCO Plus monitoring system, while the PiCCO-VoLEF monitor system was applied to measure the pulmonary arterial pressure (PAP), and calculate RHEDV and LHEDV, systemic vascular resistance index (SVRI) and pulmonary vascular resistance index (PVRI). All haemodynamic parameters were indexed for body surface area or body weight. These techniques were previously used and validated in an accompanying study (Molnár et al. 2011). A detailed description of the transpulmonary thermodilution and volumetric analysis is provided elsewhere (Phillips et al. 2009).

\subsection{Evaluation of intestinal microcirculation: $\mathrm{pCO}_{2}$ gap measurements}

A difference between local tissue and arterial $\mathrm{pCO}_{2}\left(\mathrm{paCO}_{2}\right)$ levels is a sensitive parameter with which to evaluate the effectiveness of therapy aimed at counteracting a microcirculatory dysfunction in the gastrointestinal tract (Kolkman et al. 2000). A silastic balloon-free tonometric probe (Tonosoft Medical Technical and R\&D Ltd., Hungary) was introduced through a small enterotomy into the intestinal lumen (Boda et al. 2006) to monitor intramucosal $\mathrm{pCO}_{2}$ levels by capnometry. For calculation of the $\mathrm{pCO}_{2}$ gap values, simultaneously taken $\mathrm{paCO}_{2}$ levels were subtracted from the tonometric $\mathrm{pCO}_{2}$ levels. Arterial and venous blood samples were taken at the baseline and after every hour, and blood-gas parameters were measured with a blood-gas analyser (Cobas b121, Roche, Austria).

\subsection{Biochemical measurements}

Five-mL blood samples were drawn from the jugular vein into chilled polypropylene tubes containing EDTA $\left(1 \mathrm{mg} \mathrm{mL} \mathrm{mL}^{-1}\right)$ as the scheduled experimental protocol. The blood samples were centrifuged at $1200 \mathrm{~g}$ for $10 \mathrm{~min}$ at $4{ }^{\circ} \mathrm{C}$. The plasma samples were next collected and stored at $-70{ }^{\circ} \mathrm{C}$ until assay. 
Big-endothelin measurements in plasma

Blood samples were collected into chilled polypropylene tubes containing EDTA. Plasma levels of big-ET, a 38 amino acid stable precursor protein of ET-1, were measured with a commercially available kit (Biochemica Hungaria Kft., Budapest, Hungary).

Tumour necrosis factor-alfa measurements in plasma

The plasma concentration of tumour necrosis factor-alfa (TNF- $\alpha$ ) was measured with a commercially available porcine ELISA kit (Biochemica Hungaria Kft., Budapest, Hungary). High-mobility group box protein-1 measurements in plasma

The plasma concentration of HMGB-1 was measured with a commercially available HMGB-1 ELISA kit (Shino-Test Corporation, Kanagawa, Japan).

\section{Histamine measurements in plasma}

Plasma histamine concentrations were determined by a commercially available enzyme-linked immunoassay (Quantikine ultrasensitive EIA kit for histamine; Biomedica Hungaria Kft, Budapest, Hungary).

\section{Plasma nitrite/nitrate level measurements}

The levels of plasma nitrite/nitrate $\left(\mathrm{NO}_{\mathrm{x}}\right)$, stable end-products of $\mathrm{NO}$, were measured by means of the Griess reaction. The assay depends on the enzymatic reduction of nitrate to nitrite, which is then converted into a coloured azo compound detected spectrophotometrically at $540 \mathrm{~nm}$ (Moshage et al. 1995).

\section{Measurement of whole-blood superoxide production}

For the whole-blood superoxide production measurements, the chemiluminometric method of Zimmermann et al. was used (Zimmermann et al. 1991). During the measurements, $10 \mu \mathrm{L}$ of whole blood was added to $1 \mathrm{~mL}$ of Hanks solution and the mixture was kept at $37{ }^{\circ} \mathrm{C}$ until assay. The chemiluminometric response was measured with a Lumat LB9507 luminometer (Berthold, Vienna, Austria) during 30 min after the addition of $100 \mu \mathrm{L}$ of lucigenin.

\section{Plasma troponin-T level measurements}

Cardiac troponin-T levels in plasma samples were measured by highly sensitive electrochemiluminescent immunoassay (ECLIA; Elecsys 2010, Roche Diagnostics GmbH, 
Mannheim, Germany). The analytical sensitivity was $5 \mathrm{ng} \mathrm{L}^{-1}$, and the intra- and interassay variations in the measured concentration range were 3.2 and $6.2 \mathrm{CV} \%$, respectively.

Myeloperoxidase activity measurement

The activity of myeloperoxidase (MPO), as a marker of tissue PMN leukocyte infiltration, was measured via intestinal biopsies (Kuebler et al. 1996). Briefly, the sample was homogenized with Tris- $\mathrm{HCl}$ buffer $(0.1 \mathrm{M}, \quad \mathrm{pH} \quad 7.4)$ containing $0.1 \mathrm{mM}$ phenylmethylsulfonyl fluoride to block tissue proteases, and then centrifuged at $4{ }^{\circ} \mathrm{C}$ for 20 min at 2000g. The MPO activities of the samples were measured at $450 \mathrm{~nm}$ (UV-1601 spectrophotometer, Shimadzu, Japan) and the data were referred to the protein content.

\section{Immunohistochemistry}

The presence of a complement C3 deposit in the small intestinal mucosa was detected by immunohistochemistry (IHC) (Girardi et al. 2003) on formalin-fixed, paraffin-embedded small intestinal sections, using rabbit polyclonal anti-complement fragment $\mathrm{C} 3 \mathrm{c}$ primary antibody (Bioss Inc, Woburn, MA, USA). The sections were deparaffinized for $5 \mathrm{~min}$, which was followed by antigen retrieval with citrate buffer for $20 \mathrm{~min}$. The activity of endogenous peroxidases was blocked with $5 \% \mathrm{H}_{2} \mathrm{O}_{2}$ for $10 \mathrm{~min}$. The non-specific interactions were inhibited during the next $30 \mathrm{~min}$ of incubation. The primary antibody was diluted 1:500 in antibody diluent for IHC (BD Pharmingen, San Diego, CA, USA). After washing of the sections, the secondary antibody was diluted 1:500 and the samples were incubated for $8 \mathrm{~min}$. Sections were counterstained with 3,3'-diaminobenzidine and haematoxylin. The entire IHC investigation was carried out with an automatic Leica Bond-max IHC instrument (Leica Microsystems, Tokyo, Japan). For quantitative analysis, immunostained sections were examined under a light microscope. The coded sections were analysed by an independent histopathology specialist. The numbers of capillaries positive for complement fragment $\mathrm{C} 3 \mathrm{c}$ were assessed at a magnification of 400x.

\subsection{Experimental protocols}

In Study I, the animals were randomly divided into two experimental groups. Group 1 $(n=7)$ served as sham-operated control, with the same time-frame and sampling as in group 2. A pericardial tamponade (group 2; n=8) was induced for $60 \mathrm{~min}$ by the intrapericardial administration of colloid solution $(60-90 \mathrm{~mL}$ hydroxyethyl starch 6\%; Fresenius Kabi Deutschland GmbH, Homburg, Germany), while the MAP was kept in the interval 40-45 
mmHg. After this period, the fluid was removed from the pericardial sac and the animals were monitored for 180 min post-tamponade.

Peripheral blood samples were taken at baseline, and then after $75 \mathrm{~min}$, after $150 \mathrm{~min}$ and at the end of the observation period $(240 \mathrm{~min})$ to detect the levels of vasoactive and inflammatory mediators (big-ET, histamine, $\mathrm{NO}_{\mathrm{x}}$, troponin-T, HMGB-1 and whole-blood superoxide production). Small intestinal tissue biopsies were taken at the end of the experiments for MPO activity measurements and IHC analysis of the complement C3 deposit.

In Study II, the animals were randomly allocated into one or other of three experimental groups with the same time-frame and sampling as in Study I. Group $1(n=6)$ served as sham-operated control, while in groups $2(n=7)$ and $3(n=6)$ cardiac tamponade was induced. Group 3 was treated with C5a antagonist AcPepA (a single administration of $4 \mathrm{mg}$ $\mathrm{kg}^{-1}$ in $5 \mathrm{~mL}$ saline $i v$ into the jugular vein in a 5 -min infusion) after $45 \mathrm{~min}$ of cardiac tamponade. AcPepA (ASGAPAPGPAGPLRPMF) containing an acetylated N-terminal alanine was synthetized and purified (> 95\% purity) by Biologica Co. Ltd. (Nagoya, Japan). The peptide was dissolved in saline and used in a concentration of $2 \mathrm{mg} \mathrm{mL}^{-1}$ as reported previously (Okada et al. 2011). Vehicle (saline) administration was applied in groups 1 and 2 by the same protocol. The beginning of tamponade is denoted as $0 \mathrm{~min}$. Blood and tissue sampling were performed during the 240 min observation period as described in Study I.

\subsection{Statistical analysis}

Data analysis was performed with a statistical software package (SigmaStat for Windows, Jandel Scientific, Erkrath, Germany). The distribution of our experimental data was analysed by the Kolmogorov-Smirnov normality test. Failure of the normality test indicated non-parametric distribution of the data. In Studies I-II, non-parametric methods were used. Friedman repeated measures analysis of variance on ranks was applied within the groups. Time-dependent differences from the baseline (time 0) for each group were assessed by Dunn's method, and differences between groups were analysed with the Mann-Whitney test (in Study I) or with Kruskal-Wallis one-way analysis of variance on ranks, followed by Dunn's method for pairwise multiple comparison (in Study II). In the Figures and Tables, median values and the $25^{\text {th }}$ (lower whisker) and $75^{\text {th }}$ (upper whisker) percentiles are given. ${ }^{*} p<0.05$ within groups $v s$ baseline values, ${ }^{\mathrm{x}} p<0.05$ between groups $v s$ sham-operated group values, ${ }^{*}<<0.05$ between AcPepA-treated group $v s$ cardiac tamponade group. 


\section{RESULTS}

\subsection{Study I - Haemodynamic and inflammatory responses after cardiac tamponade}

\subsubsection{Changes in haemodynamics}

In the sham-operated group, there were no significant haemodynamic changes as compared with the baseline values, and the mediator levels did not change significantly during the observation period.

The MAP was maintained in the interval $40-45 \mathrm{mmHg}$ during the tamponade for 60 min (Figure 2A) by the infusion of colloid fluid into the pericardial sac, which resulted in a significant, approximately $60 \%$ decline in $\mathrm{CO}$ in the group undergoing cardiac tamponade. The SVRI and HR were increased significantly (by 32\% and 66\%, respectively; Table 1). After relief of the tamponade, the MAP was significantly lower in the cardiac tamponade group as compared with the control group, while the $\mathrm{CO}$ and $\mathrm{HR}$ returned to the baseline despite the reduced MAP.

Table 1. Effects of cardiac tamponade on the CO, HR and SVRI. Values are medians (25th percentile; 75 th percentile). ${ }^{*} p<0.05$ within group; ${ }^{\mathrm{X}} p<0.05$ between groups $v s$ control group;

\begin{tabular}{|c|c|c|c|c|c|c|c|}
\hline & $-5 \min$ & $30 \mathrm{~min}$ & $60 \mathrm{~min}$ & $90 \mathrm{~min}$ & $120 \mathrm{~min}$ & $180 \mathrm{~min}$ & 240 min \\
\hline \multicolumn{8}{|c|}{$\mathrm{CO}\left[\mathrm{L} \mathrm{min} \mathrm{mi}^{-1}\right]$} \\
\hline $\begin{array}{c}\text { Sham- } \\
\text { operated }\end{array}$ & $\begin{array}{c}2.60 \\
(2.39 ; 2.97)\end{array}$ & $\begin{array}{c}2.73 \\
(2.25 ; 3.34)\end{array}$ & $\begin{array}{c}2.74 \\
(2.30 ; 3.14)\end{array}$ & $\begin{array}{c}2.85 \\
(2.60 ; 3.28)\end{array}$ & $\begin{array}{c}2.94 \\
(2.65 ; 3.30)\end{array}$ & $\begin{array}{c}2.85 \\
(2.51 ; 3.35)\end{array}$ & $\begin{array}{c}2.82 \\
(2.62 ; 3.33)\end{array}$ \\
\hline $\begin{array}{c}\text { Cardiac } \\
\text { tamponade }\end{array}$ & $\begin{array}{c}2.82 \\
(2.46 ; 3.01)\end{array}$ & $\begin{array}{c}1.36 * \mathrm{x} \\
(0.95 ; 1.89)\end{array}$ & $\begin{array}{c}1.19 * \mathrm{x} \\
(1.03 ; 1.30)\end{array}$ & $\begin{array}{c}2.44 \\
(2.29 ; 3.01)\end{array}$ & $\begin{array}{c}2.48 \\
(2.16 ; 3.03)\end{array}$ & $\begin{array}{c}2.40 \\
(2.13 ; 2.74)\end{array}$ & $\begin{array}{c}2.40 \\
(2.07 ; 2.79)\end{array}$ \\
\hline \multicolumn{8}{|c|}{$\mathrm{HR}\left[\right.$ beat $\left.\mathrm{min}^{-1}\right]$} \\
\hline $\begin{array}{l}\text { Sham- } \\
\text { operated }\end{array}$ & $\begin{array}{c}124 \\
(120 ; 137)\end{array}$ & $\begin{array}{c}128 \\
(118 ; 134)\end{array}$ & $\begin{array}{c}125 \\
(119 ; 134)\end{array}$ & $\begin{array}{c}126 \\
(115 ; 137)\end{array}$ & $\begin{array}{c}127 \\
(104 ; 135)\end{array}$ & $\begin{array}{c}120 \\
(104 ; 128)\end{array}$ & $\begin{array}{c}122 \\
(106 ; 126)\end{array}$ \\
\hline $\begin{array}{c}\text { Cardiac } \\
\text { tamponade }\end{array}$ & $\begin{array}{c}113 \\
(103 ; 118)\end{array}$ & $\begin{array}{c}175 * \mathrm{X} \\
(136 ; 203)\end{array}$ & $\begin{array}{c}188 * \mathrm{X} \\
(173 ; 206)\end{array}$ & $\begin{array}{c}125 \\
(122 ; 143)\end{array}$ & $\begin{array}{c}118 \\
(113 ; 120)\end{array}$ & $\begin{array}{c}114 \\
(105 ; 116)\end{array}$ & $\begin{array}{c}113 \\
(98 ; 122)\end{array}$ \\
\hline \multicolumn{8}{|c|}{$\mathrm{SVRI}\left[\mathrm{mmHg} \mathrm{mL} \mathrm{min}^{-1} \mathrm{~kg}^{-1}\right]$} \\
\hline $\begin{array}{l}\text { Sham- } \\
\text { operated }\end{array}$ & $\begin{array}{c}0.79 \\
(0.73 ; 0.83)\end{array}$ & $\begin{array}{c}0.81 \\
(0.75 ; 0.85)\end{array}$ & $\begin{array}{c}0.74 \\
(0.69 ; 0.79)\end{array}$ & $\begin{array}{c}0.68 \\
(0.66 ; 0.77)\end{array}$ & $\begin{array}{c}0.64 \\
(0.58 ; 0.68)\end{array}$ & $\begin{array}{c}0.66 \\
(0.57 ; 0.71)\end{array}$ & $\begin{array}{c}0.67 \\
(0.61 ; 0.75)\end{array}$ \\
\hline $\begin{array}{c}\text { Cardiac } \\
\text { tamponade }\end{array}$ & $\begin{array}{c}0.78 \\
(0.71 ; 0.92)\end{array}$ & $\begin{array}{c}0.91 \\
(0.80 ; 0.94)\end{array}$ & $\begin{array}{c}1.03 * \\
(0.84 ; 1.06)\end{array}$ & $\begin{array}{c}0.83 \\
(0.72 ; 0.85)\end{array}$ & $\begin{array}{c}0.83^{\mathrm{X}} \\
(0.69 ; 0.93)\end{array}$ & $\begin{array}{c}0.82^{\mathrm{X}} \\
(0.73 ; 0.91)\end{array}$ & $\begin{array}{c}0.79 \\
(0.71 ; 0.91)\end{array}$ \\
\hline
\end{tabular}



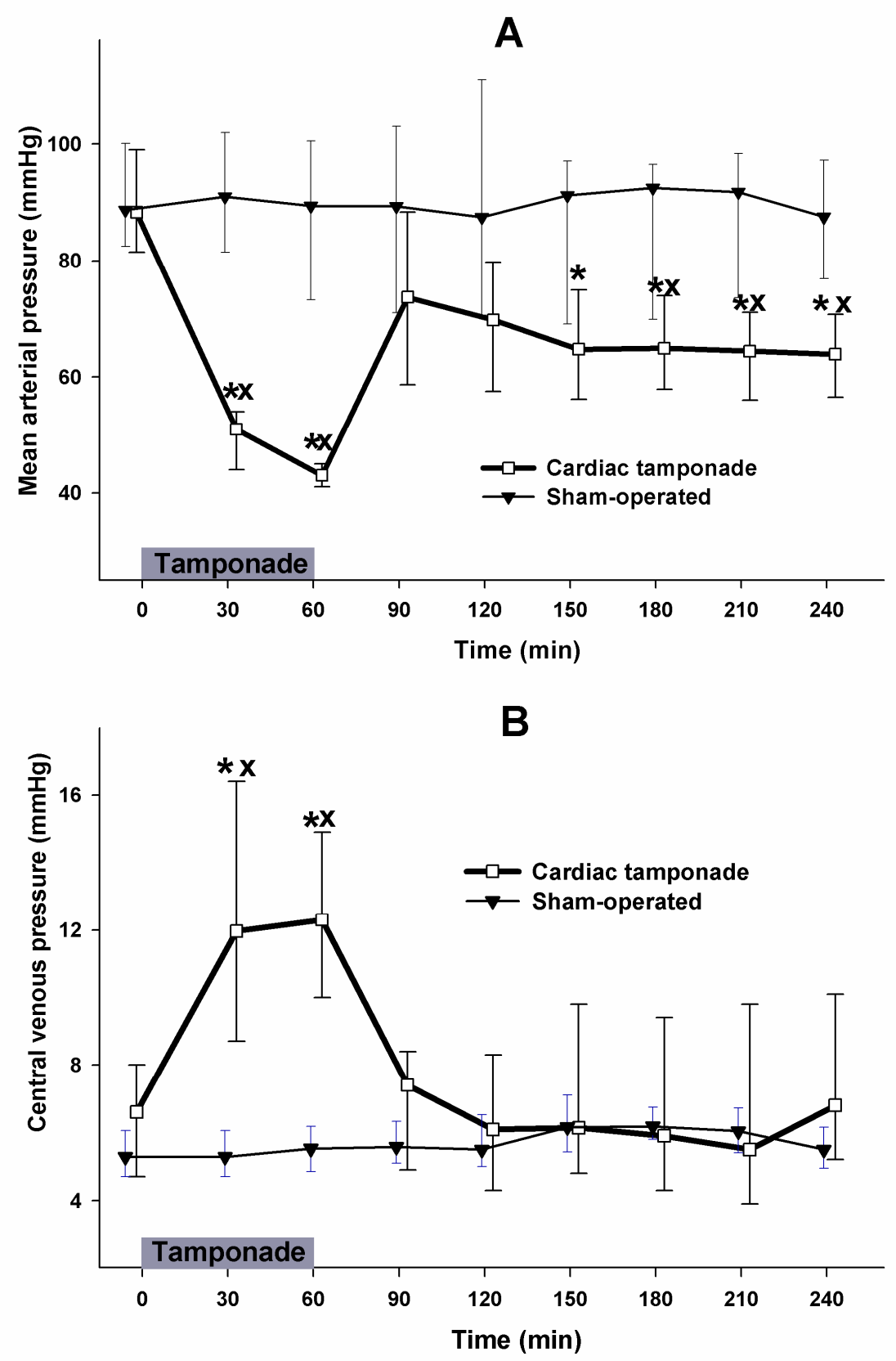

Figure 2. Changes in mean arterial pressure $(\mathbf{A})$ and central venous pressure $(\mathbf{B})$ in the shamoperated (triangles with thin continuous line) and cardiac tamponade (squares with thick solid line) groups. The box indicates the duration of the cardiac tamponade.

The decline in the venous return during the tamponade was evidenced by the increased CVP (Figure 2B). This process was accompanied by decreases in RHEDV and LHEDV (Figure 3AB). After relief of the tamponade, the CVP and RHEDV normalized, but the LHEDV did not reach the baseline value in the tamponade group; it remained significantly 
lower as compared with the sham-operated group (Figures 3AB). These changes demonstrate the long-lasting impairment of the LV function following the cardiac tamponade.
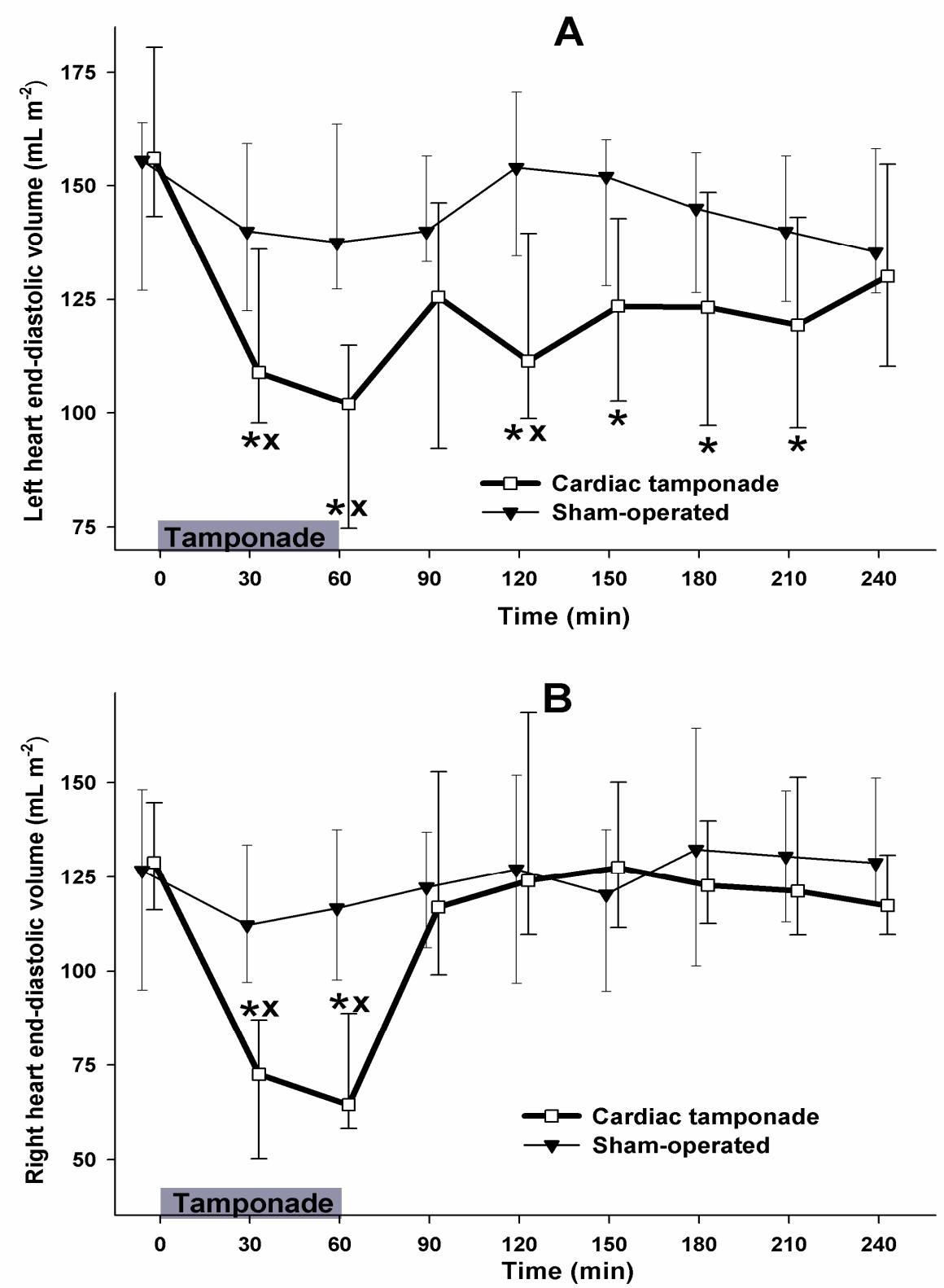

Figure 3. Changes in right heart end-diastolic volume (A) and left heart end-diastolic volume (B) in the sham-operated (triangles with thin continuous line) and cardiac tamponade (squares with thick solid line) groups. The box indicates the duration of the cardiac tamponade.

The cardiac tamponade resulted in a significant, transient decrease in PAP and a 2-fold elevation of the PVRI (Table 2). In the post-tamponade period, further long-lasting significant increases in PVRI and PAP occurred as compared with the sham-operated group, while the EVLWI was significantly elevated at the end of the observation period (Table 2). 
Table 2. Effects of cardiac tamponade on PAP, PVRI and EVLWI. Values are medians (25th percentile; 75 th percentile). ${ }^{*} p<0.05$ within group; ${ }^{\mathrm{X}} p<0.05$ between groups $v s$ control group;

\begin{tabular}{|c|c|c|c|c|c|c|c|}
\hline & $-5 \mathrm{~min}$ & $30 \mathrm{~min}$ & $60 \mathrm{~min}$ & $90 \mathrm{~min}$ & $120 \mathrm{~min}$ & $180 \mathrm{~min}$ & $240 \min$ \\
\hline \multicolumn{8}{|c|}{$\mathrm{PAP}[\mathrm{mmHg}]$} \\
\hline $\begin{array}{l}\text { Sham- } \\
\text { operated }\end{array}$ & $\begin{array}{c}30.6 \\
(27.0 ; 35.0)\end{array}$ & $\begin{array}{c}31.1 \\
(27.3 ; 35.4)\end{array}$ & $\begin{array}{c}28.9 \\
(27.5 ; 35.6)\end{array}$ & $\begin{array}{c}31.2 \\
(26.0 ; 36.0)\end{array}$ & $\begin{array}{c}30.3 \\
(27.4 ; 34.8)\end{array}$ & $\begin{array}{c}30.3 \\
(26.8 ; 32.5)\end{array}$ & $\begin{array}{c}30.8 \\
(28.3 ; 33.6)\end{array}$ \\
\hline $\begin{array}{l}\text { Cardiac } \\
\text { tamponade }\end{array}$ & $\begin{array}{c}30.4 \\
(27.3 ; 34.2)\end{array}$ & $\begin{array}{c}24.3 * x \\
(21.1 ; 27.8)\end{array}$ & $\begin{array}{c}30.0 \\
(19.2 ; 35.6)\end{array}$ & $\begin{array}{c}38.4 \\
(30.0 ; 41.3)\end{array}$ & $\begin{array}{c}36.5 \\
(34.4 ; 42.7)\end{array}$ & $\begin{array}{c}41.2 * x \\
(35.3 ; 43.2)\end{array}$ & $\begin{array}{c}37.9 \\
(31.9 ; 42.8)\end{array}$ \\
\hline \multicolumn{8}{|c|}{ PVRI $\left[\mathrm{mmHg} \mathrm{mL}^{-1} \mathrm{~min}^{-1} \mathrm{~kg}^{-1}\right]$} \\
\hline $\begin{array}{l}\text { Sham- } \\
\text { operated }\end{array}$ & $\begin{array}{c}0.37 \\
(0.31 ; 0.39)\end{array}$ & $\begin{array}{c}0.35 \\
(0.30 ; 0.43)\end{array}$ & $\begin{array}{c}0.31 \\
(0.29 ; 0.35)\end{array}$ & $\begin{array}{c}0.29 \\
(0.25 ; 0.35)\end{array}$ & $\begin{array}{c}0.29 \\
(0.25 ; 0.32)\end{array}$ & $\begin{array}{c}0.32 \\
(0.24 ; 0.36)\end{array}$ & $\begin{array}{c}0.31 \\
(0.23 ; 0.38)\end{array}$ \\
\hline $\begin{array}{l}\text { Cardiac } \\
\text { tamponade }\end{array}$ & $\begin{array}{c}0.41 \\
(0.26 ; 0.50)\end{array}$ & $\begin{array}{c}0.75 * x \\
(0.66 ; 0.98)\end{array}$ & $\begin{array}{c}0.88 * \mathrm{x} \\
(0.81 ; 0.95)\end{array}$ & $\begin{array}{c}0.48^{\mathrm{X}} \\
(0.42 ; 0.53)\end{array}$ & $\begin{array}{c}0.51^{\mathrm{x}} \\
(0.44 ; 0.63)\end{array}$ & $\begin{array}{c}0.54^{\mathrm{x}} \\
(0.49 ; 0.60)\end{array}$ & $\begin{array}{c}0.49^{\mathrm{X}} \\
(0.47 ; 0.54)\end{array}$ \\
\hline \multicolumn{8}{|c|}{$\mathrm{EWLV}\left[\mathrm{mL} \mathrm{kg}^{-1}\right]$} \\
\hline $\begin{array}{l}\text { Sham- } \\
\text { operated }\end{array}$ & $\begin{array}{c}8.0 \\
(7.8 ; 9.0)\end{array}$ & $\begin{array}{c}8.2 \\
(8.0 ; 9.0)\end{array}$ & $\begin{array}{c}8.5 \\
(8.0 ; 9.0)\end{array}$ & $\begin{array}{c}8.5 \\
(8.0 ; 9.1)\end{array}$ & $\begin{array}{c}8.5 \\
(8.0 ; 9.1)\end{array}$ & $\begin{array}{c}8.4 \\
(8.0 ; 9.0)\end{array}$ & $\begin{array}{c}8.4 \\
(8.0 ; 9.0)\end{array}$ \\
\hline $\begin{array}{l}\text { Cardiac } \\
\text { tamponade }\end{array}$ & $\begin{array}{c}8.0 \\
(8.0 ; 9.0)\end{array}$ & $\begin{array}{c}8.0 \\
(7.5 ; 8.8)\end{array}$ & $\begin{array}{c}8.0 \\
(7.3 ; 8.9)\end{array}$ & $\begin{array}{c}8.5 \\
(8.0 ; 10.8)\end{array}$ & $\begin{array}{c}9.0 \\
(8.3 ; 10.8)\end{array}$ & $\begin{array}{c}9.5 * \\
(8.5 ; 10.0)\end{array}$ & $\begin{array}{c}10.0 * \mathrm{x} \\
(9.0 ; 11.0)\end{array}$ \\
\hline
\end{tabular}

The significant decrease in SMA blood flow during the tamponade indicated a deteriorated mesenteric circulation. After the removal of the pericardiac fluid, the SMA flow returned to the control values (Figure 4A).

The $\mathrm{pCO}_{2}$ gap, the difference between the local tissue and the arterial $\mathrm{pCO}_{2}$, is a reliable index of local tissue perfusion. The $\mathrm{pCO}_{2}$ gap increased significantly during the tamponade, while relief of the tamponade resulted in a significantly lower gap, though the values remained significantly higher than that for the sham-operated control group throughout the post-tamponade period (Figure 4B). 

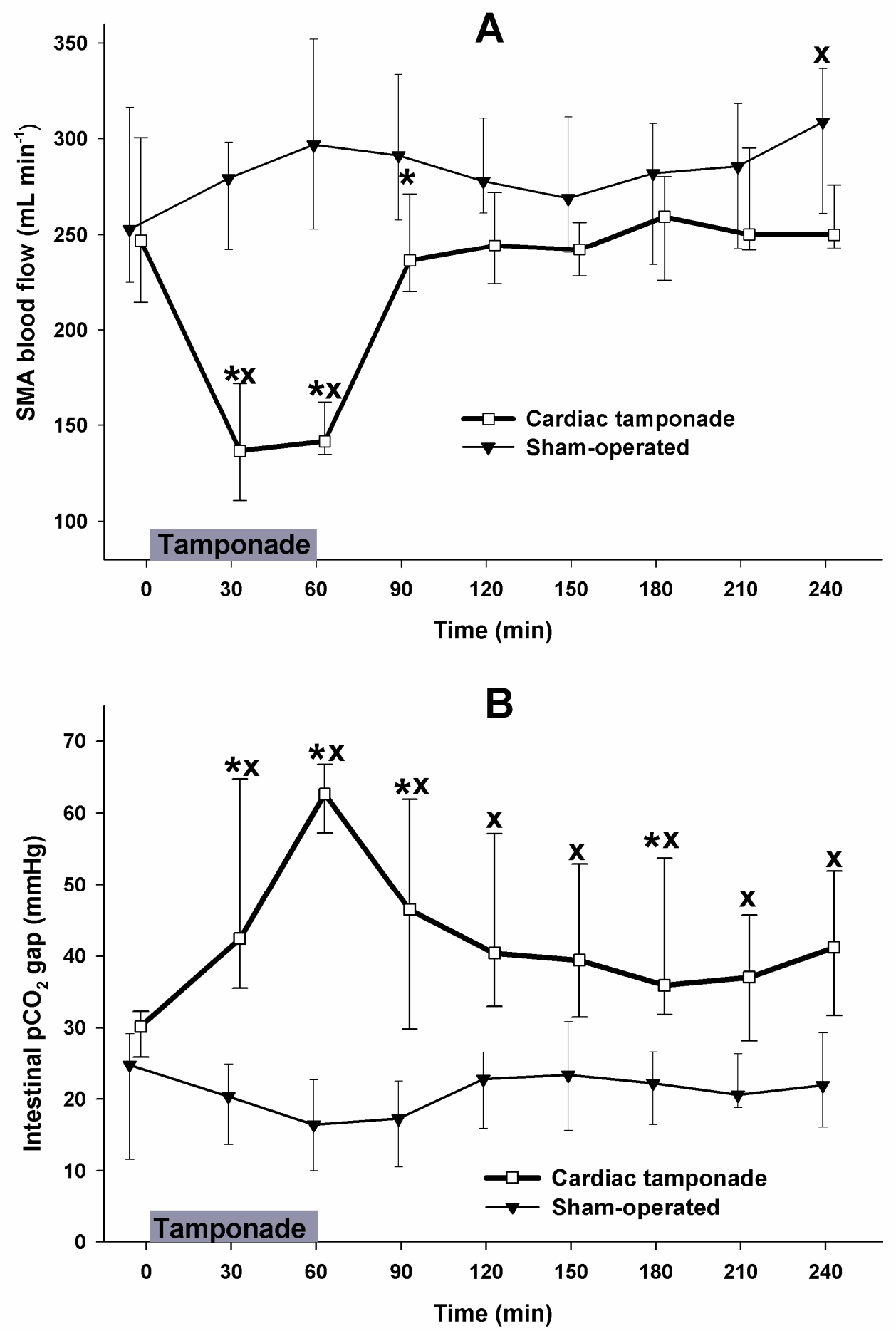

Figure 4. Changes in superior mesenteric artery (SMA) blood flow (A) and intestinal $\mathrm{pCO}_{2}$ gap (B) in the sham-operated (triangles with thin continuous line) and cardiac tamponade (squares with thick solid line) groups. The box indicates the duration of the cardiac tamponade. 


\subsubsection{Changes in biochemical parameters}

In the cardiac tamponade group, increased superoxide radical production was observed at the beginning of the post-tamponade phase (Figure 5). In parallel, the plasma histamine levels were increased significantly by 75 and $240 \mathrm{~min}$ of the observation period: $\mathrm{M}=16.2 \mathrm{nM}$ (p25=15.5; p75=16.6) and $\mathrm{M}=10.3 \mathrm{nM}$ (p25=9.1; p75=12.8), respectively, vs the baseline $(\mathrm{M}=7.5$; $\mathrm{p} 25=6.4 ; \mathrm{p} 75=8.8)$, or $v s$ the corresponding value for the sham-operated group $(\mathrm{M}=7.4 \mathrm{nM} ; \mathrm{p} 25=5.7 ; \mathrm{p} 75=9.4)$.

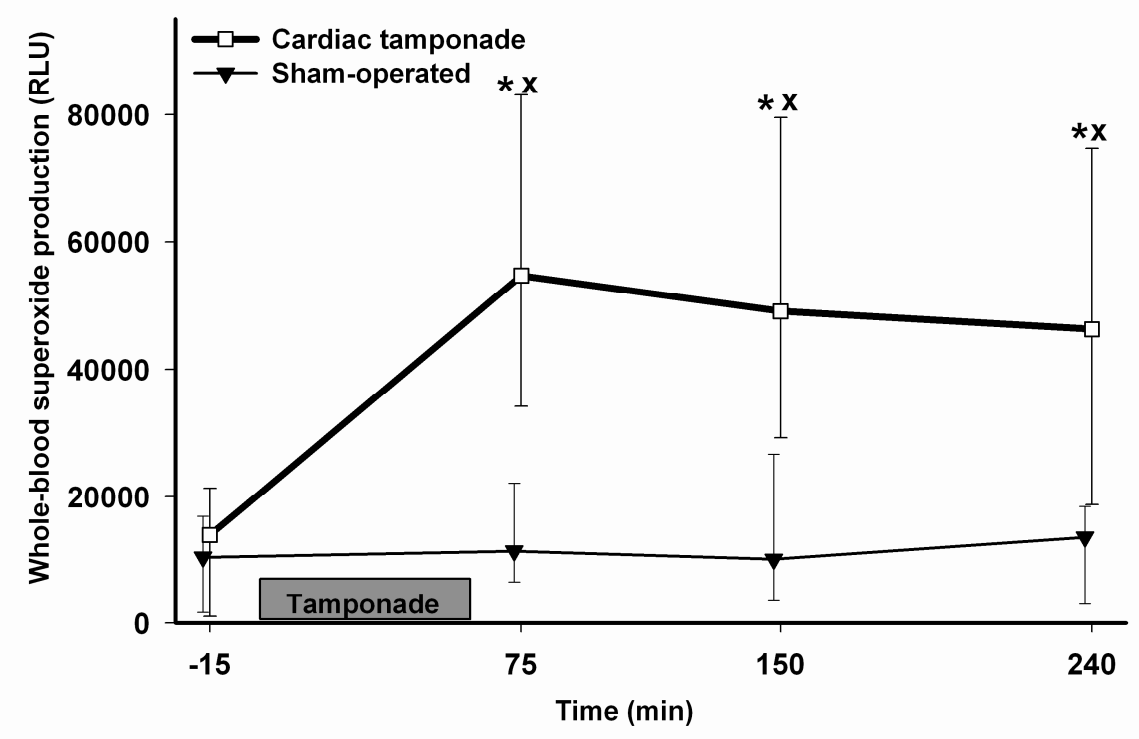

Figure 5. Changes in whole-blood superoxide production in the sham-operated (triangles with thin continuous line) and cardiac tamponade (squares with thick solid line) groups. The box indicates the duration of the cardiac tamponade.

The $\mathrm{NO}_{\mathrm{x}}$ concentration in the plasma allows an estimate of the changes in NO production. The consequence of the cardiac tamponade in this respect was a slight, but statistically significant increase in $\mathrm{NO}_{\mathrm{x}}$ level at the end of the post-tamponade period as compared with the baseline level and with that for the sham-operated group (data not shown). 

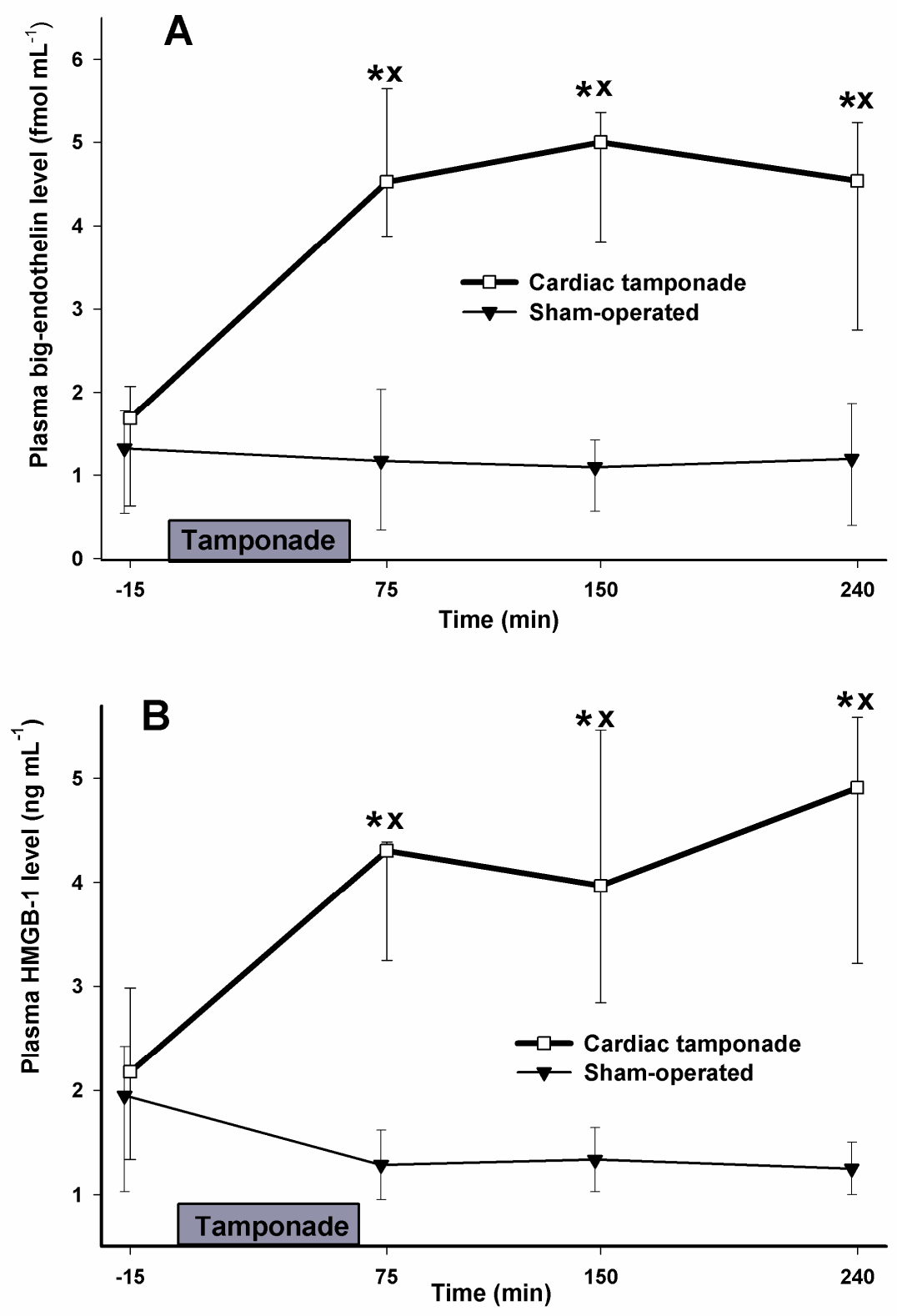

Figure 6. Changes in plasma big-endothelin (ET) concentration (A) and high-mobility group box protein-1 (HMGB-1) level (B) in the sham-operated (triangles with thin continuous line) and cardiac tamponade (squares with thick solid line) groups. The box indicates the duration of the cardiac tamponade.

Big-ET is a stable precursor of ET-1 with a longer half-life. The plasma big-ET level increased significantly (4-5-fold) in response to the cardiac tamponade (Figure 6A).

HMGB-1 is an effective signal for leukocyte activation, which causes an escalation of the inflammatory process. The plasma level of HMGB-1 was elevated significantly after the compression of the heart (Figure 6B). 
The rate of PMN leukocyte accumulation was determined through measurement of the MPO activity of the intestinal tissue samples taken at the end of the experiments. The level of MPO activity was significantly higher in the small intestinal tissue samples of the cardiac tamponade group, indicating the increased accumulation of PMN leukocytes (cardiac tamponade: $\mathrm{M}=5.37$ (p25=4.8; $\mathrm{p} 75=6.22 ; \mathrm{U}$ mg protein ${ }^{-1}$ ) vs sham-operated: $\mathrm{M}=2.84$ (p25=2.19; p75=3.22).

The troponin-T level in the plasma allows an estimate of the cardiomyocyte damage. The mean concentrations of troponin-T were significantly increased after the compression of the heart and at the end of the post-tamponade period as compared with the baseline and with those for the sham-operated group (Figure 7).

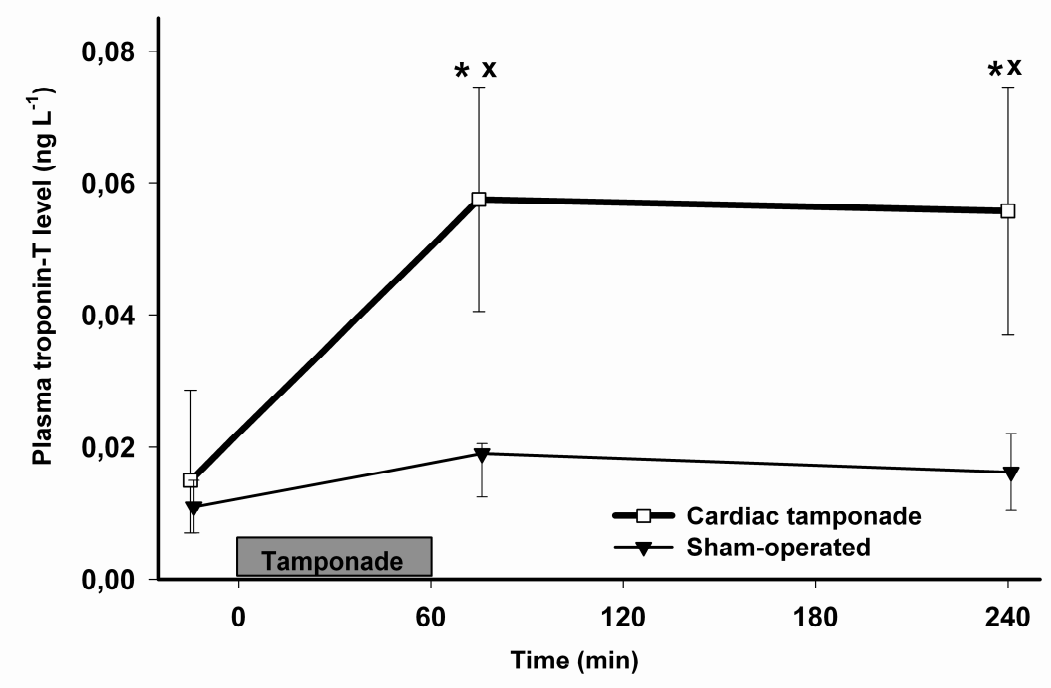

Figure 7. Changes in plasma troponin-T level in the sham-operated (triangles with thin continuous line) and cardiac tamponade (squares with thick solid line) groups. The box indicates the duration of the cardiac tamponade.

Activation of the complement cascade was evaluated by the presence of a complement C3 deposit in the small intestinal mucosa with the IHC method (Figure 8). In each field of view of the slides, the number of capillaries showing C3 deposit positivity was counted. The number of C3 deposits was significantly higher in the tamponade group than in the shamoperated group $(M=3 ; p 25=1 ; p 75=4.5$ vs $M=0 ; p 25=0 ; p 75=1$ deposits/field of view). 

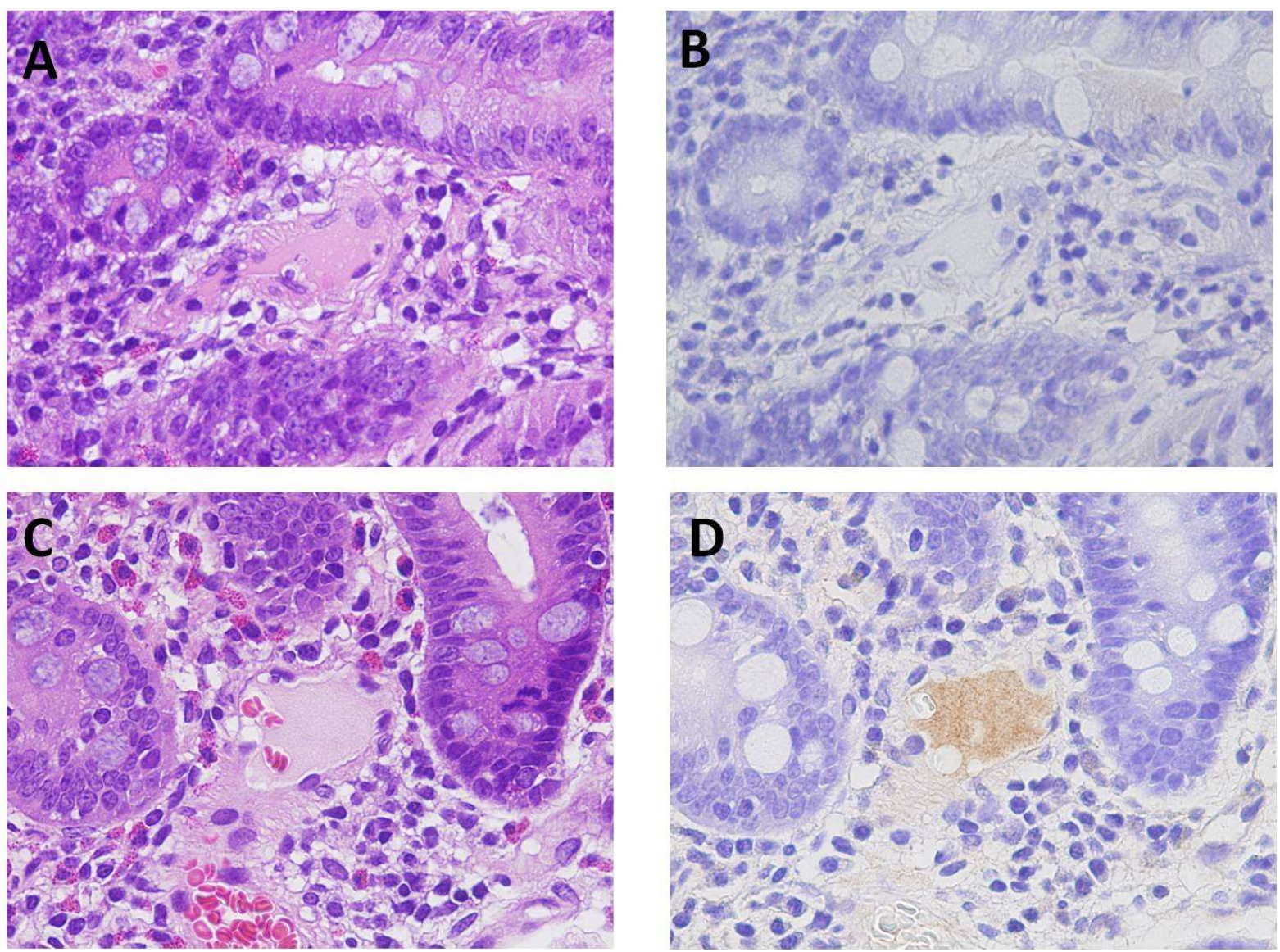

Figure 8. Changes in complement $\mathrm{C} 3$ deposition as demonstrated by IHC analyses in the small intestinal mucosal biopsies taken at the end of the experiments: H\&E staining in the sham-operated (A) and cardiac tamponade (C) groups; extensive C3 deposition with IHC staining in the cardiac tamponade (D) group as compared with the sham-operated (B) group.

\subsection{Study II - Cardiac effects of complement C5a antagonist treatment}

\subsubsection{Changes in cardiac and pulmonary haemodynamics}

In the sham-operated group, there were no significant haemodynamic changes as compared with the baseline values, and the mediator levels did not change significantly during the observation period.

MAP was kept in the interval $40-45 \mathrm{mmHg}$ during cardiac tamponade for $60 \mathrm{~min}$ (Figure 9A) by the infusion of colloid fluid into the pericardial sac, and this resulted in a significant $65 \%$ decline in $\mathrm{CO}$ in both groups undergoing cardiac tamponade (Figure 9B) and a significant increase in HR (Figure 10B). After relief of the tamponade, the MAP was significantly lower in the non-treated cardiac tamponade group as compared with the control group, while the $\mathrm{CO}$ and $\mathrm{HR}$ returned to the baseline values despite the reduced MAP. 
Administration of AcPepA after 45 min of the cardiac tamponade resulted in an elevation of the MAP, did not influence the $\mathrm{CO}$, and caused a significant decrease in the HR as compared with the untreated cardiac tamponade group in the post-tamponade period (Figures 9A-B and 10B).
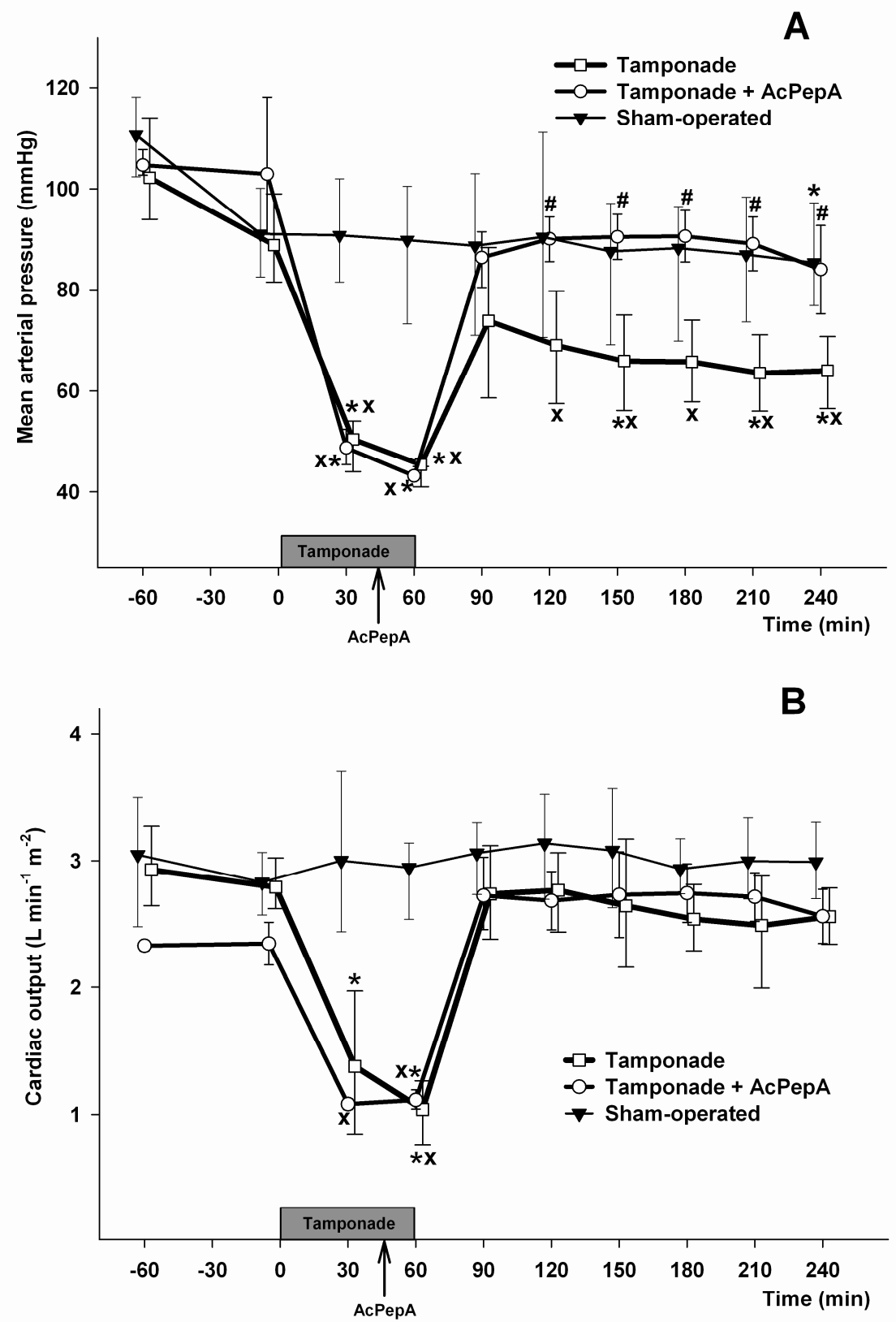

Figure 9. Changes in mean arterial pressure (A) and cardiac output (B) in the sham-operated (solid triangles with continuous line), cardiac tamponade (empty squares with solid line) and AcPepA-treated (empty circles with solid line) groups. The box indicates the duration of the cardiac tamponade, and the arrow indicates the time of treatment with AcPepA. 
The decline in the venous return during the tamponade was evidenced by the increased CVP (Figure 2B). This process was accompanied by a decrease in GEDV (Figure 10A). The GEDV did not reach the baseline values in the non-treated cardiac tamponade group (Figure 10A) after relief of the tamponade. These changes demonstrate the long-lasting impairment of the venous return flow following the cardiac tamponade. After AcPepA administration, we observed significant increases in the preload parameters in the post-tamponade period: the CVP was set to a significantly higher level (Annex II, Figure 2A) and the GEDV demonstrated the increased returning blood flow (Figure 10A).
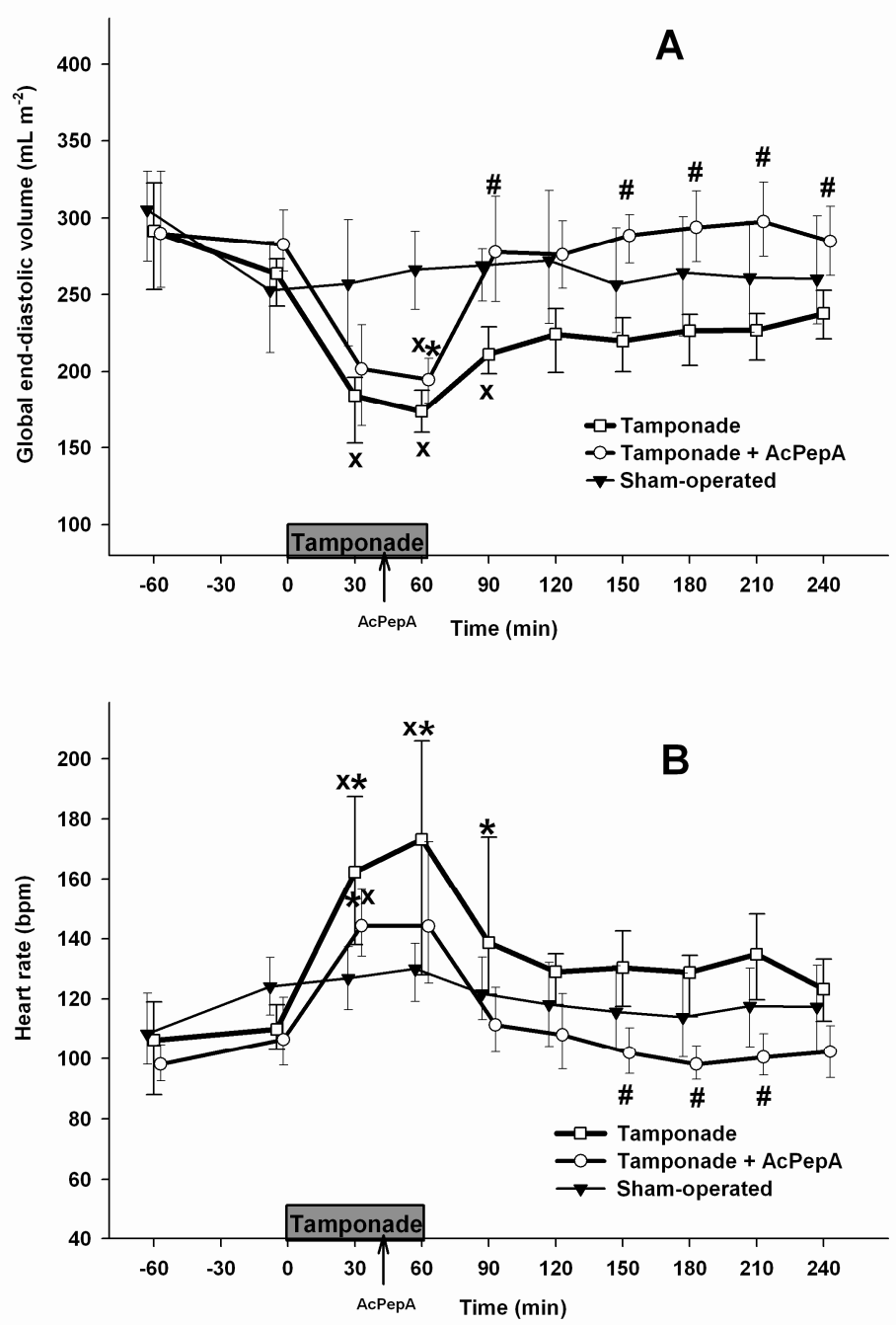

Figure 10. Changes in global end-diastolic volume (A) and heart rate (B) in the shamoperated (solid triangles with continuous line), cardiac tamponade (empty squares with solid line) and AcPepA-treated (empty circles with solid line) groups. The box indicates the duration of the cardiac tamponade, and the arrow indicates the time of treatment with AcPepA. 
The cardiac tamponade caused a permanent impairment of the LV function, as demonstrated by the long-lasting decrease in LHEDV (Figure 11). Administration of AcPepA after $45 \mathrm{~min}$ of the cardiac tamponade normalized the LHEDV as compared with the untreated cardiac tamponade group in the post-tamponade period. In contrast with the LHEDV, the RHEDV returned to the baseline level after the relief of the tamponade (Figure 3B) and it was not influenced by complement C5a antagonist treatment (data not shown).

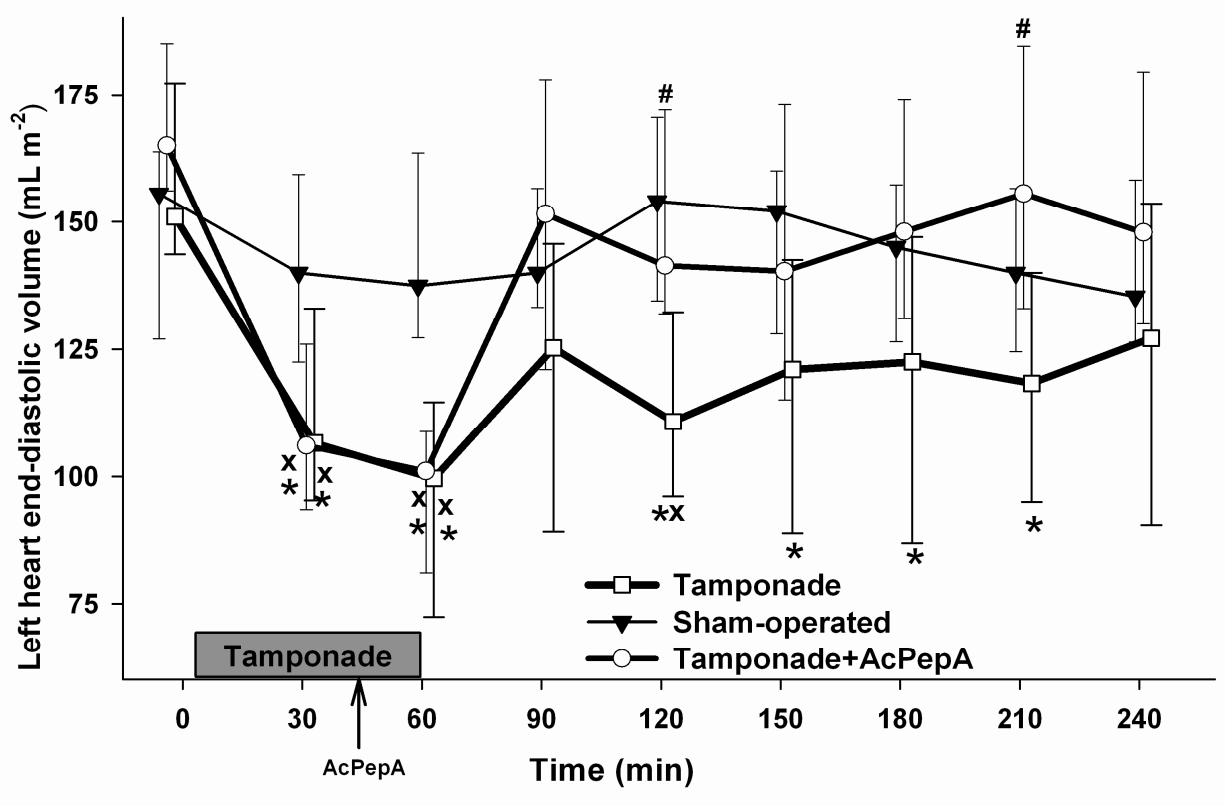

Figure 11. Changes in left heart end-diastolic volume in the sham-operated (solid triangles with continuous line), cardiac tamponade (empty squares with solid line) and AcPepA-treated (empty circles with solid line) groups. The box indicates the duration of the cardiac tamponade, and the arrow indicates the time of treatment with AcPepA.

The cardiac tamponade caused significant changes in the pulmonary circulation in both the tamponade and the post-tamponade periods (Table 2). AcPepA treatment decreased the long-lasting elevations in PAP and PVRI that occurred after the relief of the tamponade as compared with the untreated cardiac tamponade group (Figure 12A,B). However, the elevation caused in EVLWI by the cardiac tamponade was not influenced significantly by this treatment at the end of the observation period (data not shown). 

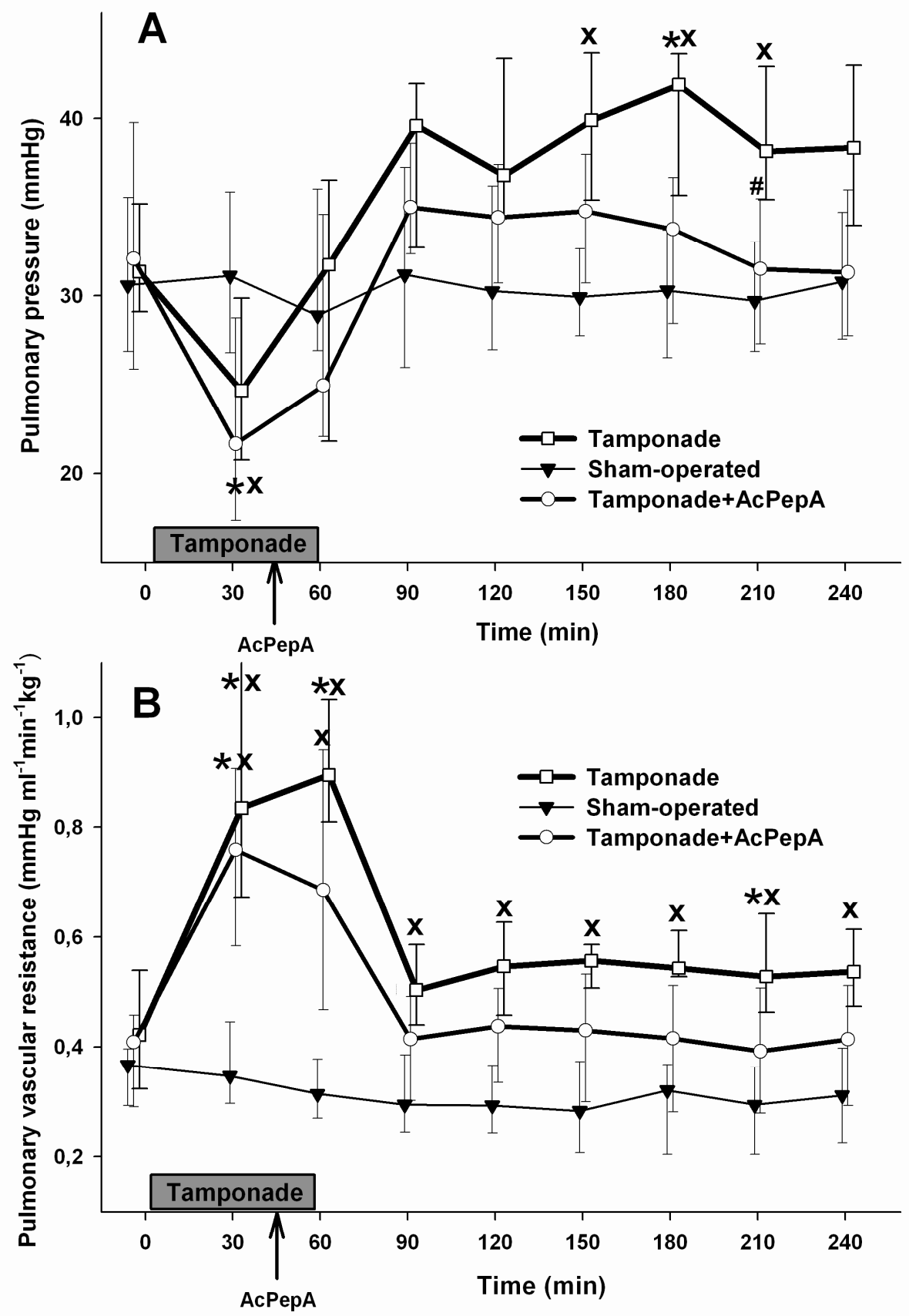

Figure 12. Changes in pulmonary arterial pressure $(\mathbf{A})$ and pulmonary vascular resistance $(\mathbf{B})$ in the sham-operated (solid triangles with continuous line), cardiac tamponade (empty squares with solid line) and AcPepA-treated (empty circles with solid line) groups. The box indicates the duration of the cardiac tamponade, and the arrow indicates the time of treatment with AcPepA. 


\subsubsection{Changes in biochemical parameters}

Change in the TNF- $\alpha$ level is a sensitive and early signal indicative of the inflammatory process. In our pig model, a 10-fold elevation in the plasma level of TNF- $\alpha$ was detected after the compression of the heart; the level then decreased successively until the end of the observation period (Figure 13A).

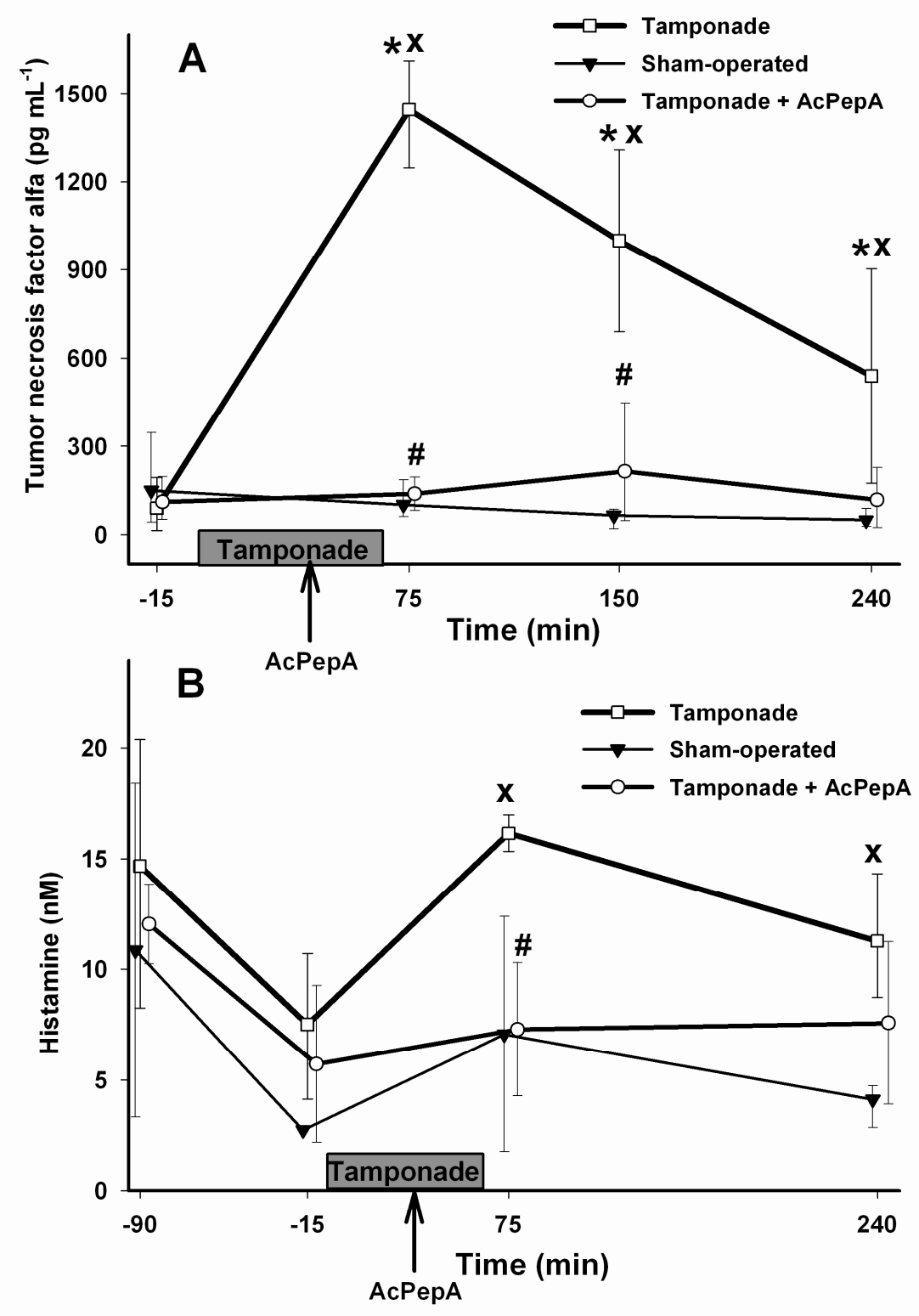

Figure 13. Changes in plasma TNF- $\alpha$ (A) and histamine (B) levels in the sham-operated (solid triangles with continuous line), cardiac tamponade (empty squares with solid line) and AcPepA-treated (empty circles with solid line) groups. The box indicates the duration of the cardiac tamponade, and the arrow indicates the time of treatment with AcPepA. 
The increased level of histamine release in the plasma suggests the activation of the hypoxia-sensitive inflammatory cells (mast cells and basophil leukocytes). As a result of the cardiac tamponade, the histamine level increased significantly by $15 \mathrm{~min}$ of the posttamponade phase (Figure 13B).

After AcPepA administration, the characteristic biochemical changes following the cardiac tamponade were significantly different. The AcPepA treatment reduced the concentrations of TNF- $\alpha$ and histamine in the plasma after the compression of the heart and in the post-tamponade period as compared with the sham-operated group (Figure 13A,B).

A measurable troponin-T level in the plasma allows an estimate of the ischaemic effect of cardiac tamponade. The cardiac tamponade caused a significant elevation in the mean concentration of troponin- $T$ after the relief of the tamponade and at the end of the posttamponade period, while the administration of AcPepA resulted in a lower level of troponin- $\mathrm{T}$ in the plasma in the post-tamponade phase (Figure 14).

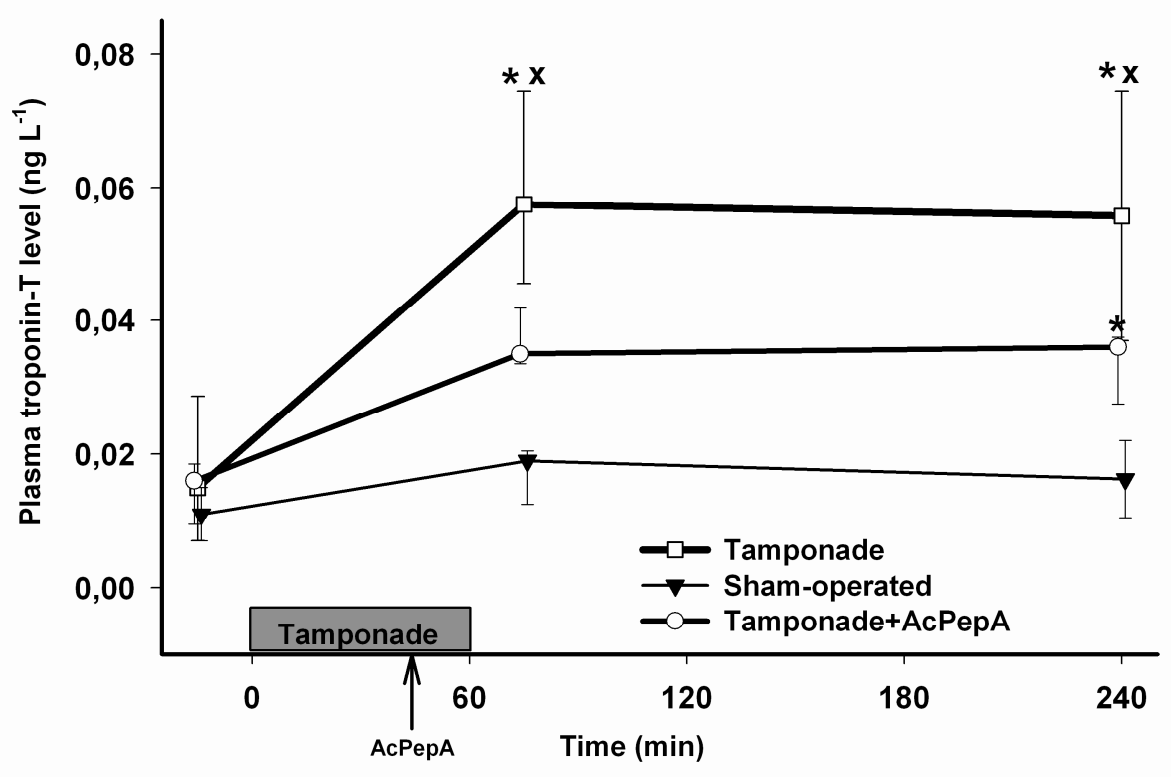

Figure 14. Changes in plasma troponin- $T$ level in the sham-operated (solid triangles with continuous line), cardiac tamponade (empty squares with solid line) and AcPepA-treated (empty circles with solid line) groups. The box indicates the duration of the cardiac tamponade, and the arrow indicates the time of treatment with AcPepA. 
Activation of the complement cascade was detected via the increased presence of a complement $\mathrm{C} 3$ deposit in the tamponade group as compared with the sham-operated group in the small intestinal mucosa with the IHC method. However, the number of capillaries displaying C3 deposit positivity was lower in the AcPepA-treated tamponade group than in the non-AcPepA-treated group (Figure 15).

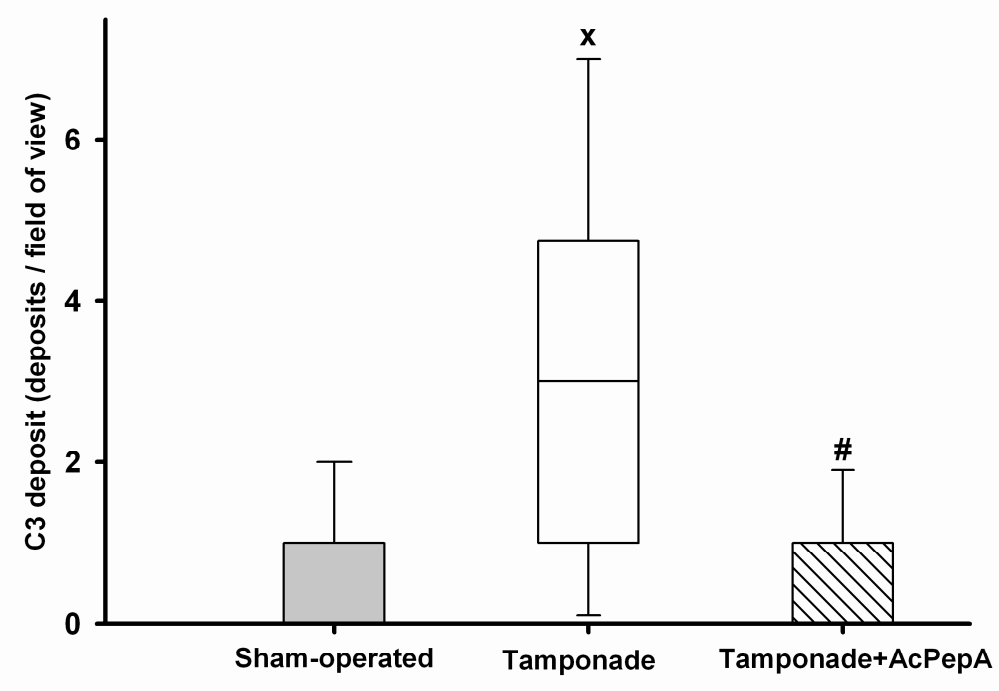

Figure 15. Changes in complement $\mathrm{C} 3$ deposition demonstrated by immunohistochemical analyses in the small intestinal mucosal biopsies taken at the end of the experiments. 


\section{DISCUSSION}

\subsection{Study I}

Pericardial tamponade is accompanied by high mortality and postoperative complication rates, even in the event of adequate treatment. In cases of blunt chest trauma, the mortality may exceed $80 \%$ (Brathwaite et al. 1990), while a $22 \%$ mortality rate was reported after elective open-heart surgery in clinically proven cases of localized cardiac tamponade (Grumann et al. 2012). Our primary goal was to characterize the haemodynamic effects of temporary mechanical compression of the heart and to outline a multi-faceted inflammatory process which may cause potential risks in the post-tamponade phase. This is required to identify the inflammatory mediators, with a potential role in this inflammatory cascade system.

The major finding of Study I is that the post-tamponade period is characterized by a decreased level of systemic perfusion and by an impaired LV function and pulmonary circulation, as evidenced by the MAP, LHEDV, PAP, PVRI and EVLWI data. The $\mathrm{pCO}_{2}$ gap changes suggested that, in parallel, a significant intestinal microcirculatory dysfunction evolved in this porcine model. More importantly, these responses were associated with abrupt increases in the level of superoxide radical production, big-ET, troponin-T, HMGB1, histamine, intestinal MPO activity and complement activation during the post-tamponade phase.

The cardiac filling disorder induced different vasoconstrictive compensatory reactions in the systemic and pulmonary circulations: the increase in PVRI (112\%) was much higher than that in SVRI (32\%). Previous experimental and clinical data suggest that the increasing pericardial pressure causes a continuous decline in coronary blood flow due to an increase in coronary vascular resistance (Klopfenstein et al. 1987, Skalidis et al. 2000). Skalidis et al. observed a decreased hyperaemic flow under increased pericardial pressure, which implies an augmented susceptibility to myocardial ischaemia (Skalidis et al. 2000). The significantly increased HR during the acute phase of the tamponade could also contribute to the cardiac hypoxia. The decreased $\mathrm{CO}$ is compensated by the increased HR, though the length of the systole does not change, while the diastole is shortened. Such a high frequency then results in less time for oxygen delivery to the cardiac muscle cells, and the degree of oxygenation of the heart is therefore worsened. The significantly elevated level of troponin- $T$ during the acute phase of the tamponade also demonstrates the deterioration of oxygenation and damage of the cardiac muscle cells. 
After the relief of the tamponade, the MAP was decreased, while the CO was kept compensated, and there were no significant differences as compared with the control group. This may be explained by the normalized preload, as evidenced by the normalized CVP and RHEDV, and the moderate elevation of the afterload. However, the significant decrease in LHEDV indicates a LV dysfunction during the post-tamponade phase. The persistent elevations in PAP and PVRI could contribute to this process, together with the lung oedema, as revealed by the elevated EVLWI. These conclusions are supported by clinical observations on early cardiac failure and pulmonary oedema after removal of the pericardial effusion (Ligero et al. 2006, Bernal et al. 2007).

In this clinically relevant large animal model, the pericardial tamponade triggered characteristic macro- and microcirculatory changes in the intestines. While the SMA flow, which reflects the blood supply of the small intestine and colon, was diminished during the tamponade, a prolonged impairment of the mucosal microcirculation was detected. This is in accordance with previous assumptions that the macro- and microhaemodynamics may change relatively independently, or may be dissociated in stress conditions (De Backer et al. 2010).

In the background of these haemodynamic alterations, a multi-faceted role of humoral mediators, including ET-1, is proposed. Hypoxia is considered to be one of the basic stimuli for ET-1 synthesis. This peptide is produced predominantly by the endothelium, but in pathophysiological states other cell types, such as leukocytes, macrophages, smooth muscle cells, cardiomyocytes and mesangial cells, can also serve as sources of its release (Boros 2003). The increased plasma level of ET-1 could be responsible for the decreased coronary perfusion (Fazekas et al. 2001) and pulmonary hypertension. The activation of vasoconstrictor ET receptors can further play a decisive role in acute microcirculatory disorders of the peripheral cardiovascular system. It has been shown that selective ET-A receptor antagonism increases the $\mathrm{CO}$, decreases the peripheral resistance (Wolfard et al. 1999, Kaszaki et al. 2008) and reduces intestinal microvascular injury and PMN leukocyte accumulation during ischaemia-reperfusion (Wolfard et al. 2002).

In addition to its independent role as a dominant vasoconstrictor, the peptide may also influence the functions of other cell types in the circulatory system. ET-1 has been reported to induce leukocyte rolling and adherence through a predominantly ET-A receptor-mediated mechanism (Boros et al. 1998). There is a close relationship between a compromised mucosal blood flow and the magnitude of PMN leukocyte-endothelial cell interactions in the intestines (Wolfard et al. 2002). On the other hand, ET-1 also causes histamine release from mast cells, which may lead to enhanced vascular permeability and a relative blood loss into the dilated 
vessels (Kaszaki et al. 2008). Histamine release in the pulmonary circulation contributes to the increase in EVLWI (Walkenstein et al. 1985), while in the splanchnic area, histamine release probably plays a role in the counter-regulation of the excessive, prolonged vasoconstriction that contributes to the lethal outcome (Kaszaki et al. 1989). Furthermore, ET-1 activates NADPH oxidase, resulting in an increased superoxide radical production (Loomis et al. 2005), which can simultaneously reduce NO production, leading to the formation of the highly cytotoxic peroxynitrite (Sheehy et al. 1998). From this point of view, the excessive release of ET-1 can be the key player as concerns the spreading inflammatory responses, when intensive complement activation is also ignited. The presence of complement C3 deposits was verified in this tamponade model and we found increased plasma levels of HMGB-1 too, the release of which is additionally directly mediated by the complement cascade. In this scenario, HMGB1 release is a further danger signal to responsive cells, which amplifies the production and secretion of other pro-inflammatory mediators and finally induces excessive inflammation (Yang et al. 2002, Ulloa and Messmer 2006).

This study has some limitations. On the one hand, thoracotomy causes severe surgical trauma. A diaphragmatic window through laparotomy could be a possible alternative to reach the pericardial cavity (Park et al. 2008). Nevertheless, safe catheterization of the pericardial sac, and quick guidance of the diagnostic instrumentation into the correct positions in the heart cavities are advantages of the open chest model. On the other hand, the inflammatory reaction may be non-specific because cardiogenic and hypovolaemic shock components are not mutually exclusive. Decreases in MAP and CO, splanchnic perfusion and microcirculatory damage may be observed in nearly all forms of circulatory shock (e.g. hypovolaemic, cardiogenic or distributive). Nevertheless, there are also tamponade-specific consequences, such as an elevation of the CVP, a decrease in LHEDV and an increased plasma troponin-T level, which may be direct signs and consequences of tamponade-induced cardiac ischaemia.

In conclusion, we have demonstrated characteristic macrohaemodynamic changes, together with apparent signs of a damaged LV function and a splanchnic inflammatory reaction after the relief of a tamponade. The evidence further suggests that numerous biomarkers, including superoxide radicals, big-ET, HMGB1, histamine, MPO activity or components of the complement system, are significant factors of the inflammatory cascade in this porcine model of pericardial tamponade. On the basis of these results, we assume that these mediators could be promising targets for therapeutic intervention in the future. 


\subsection{Study II}

It is widely accepted that inflammatory activation plays a decisive role in low-flow conditions, although the potential of 'anti-inflammatory' compounds to prevent or cure low perfusion-induced in vivo processes is very limited. With this objective, Study II was designed to develop adjuvant therapy which is able to improve the early haemodynamic and inflammatory changes that occur after restoration of the cardiac tamponade. Numerous experimental results (Ward 2008; Sarma and Ward 2011), together with our findings from Study I, suggested that the components of the complement system could be promising targets for therapeutic intervention. For this purpose, we planned to use the early inhibition of complement C5a with AcPepA, a synthetic, antisense, 17-amino acid peptide acetylated at the N-terminal alanine (Okada et al. 2007), during the acute phase of cardiac tamponade. It has been shown that this compound is capable of binding directly to C5a (in its 37-53 amino acid region) in a concentration-dependent manner. The binding between the molecules is very strong (the dissociation requires treatment with $6 \mathrm{M}$ urea in vitro) (Fujita et al. 2004). AcPepA has proved to be effective in a pilot primate endotoxin shock model (Okada et al. 2011).

The major findings of Study II are that the early inhibition of complement C5a with AcPepA effectively restored the impaired LV function and pulmonary circulation in the posttamponade period. More importantly, these responses were associated with significant decreases in the plasma levels of troponin-T, TNF- $\alpha$, histamine and complement activation in the tissues after the relief of the cardiac tamponade.

In a relevant study, a significantly increased level of C5a was demonstrated at the beginning of reperfusion, followed by a sudden decrease. The harmful consequences are evoked during this short, but decisive period (Eppinger et al. 1997). The relatively short biological half-life (around $30 \mathrm{~min}$ ) of AcPepA supports the application of this peptide in this time frame. In this line, the study was designed to investigate the effects of a single administration, since its major effects were expected at the very beginning of the reoxygenation. Our IHC examination data clearly revealed that the timing of AcPepA treatment in our pig model was effective, with a decreased level of $\mathrm{C} 3$ positivity in the AcPepA-treated tamponade group. These early effects may result in further, longer-term alterations, but as a first step we aimed to identify the key factors in the acute phase of central circulatory failure.

After the relief of the cardiac tamponade, the MAP remained at a decreased level, while the CO did not show any significant differences relative to the control group. This was 
due to the elevated HR, which is indicative of the increased strain of the heart muscle. Following AcPepA treatment, the MAP was elevated to the control level and the $\mathrm{CO}$ was also maintained. Thus, the most pronounced differences between the compensatory mechanisms of the AcPepA-treated and non-treated tamponade groups were the restored MAP and the lower HR. This seems to be especially crucial if we consider the fact that the circulation of the heart muscle is provided during the diastolic phase, and nearly stops during systole. If the HR is increased, the length of the systole does not change, while the diastole is shortened. The higher the frequency, the shorter the time available for oxygen delivery to the cardiac muscle cells, and therefore a lower HR and maintained CO provide better oxygenation for the heart. The elevated GEDV in the treated group also indicates that the main compensatory mechanism in this early phase is switched from an increased afterload to an elevation of the preload.

It could be supposed that improvements of the LV function and pulmonary circulation play a decisive role in the background of this process. It has been demonstrated that elevation of the PVR reduces the CO, because of the increase in RV afterload leading to an impaired LV function (Avontuur et al. 1998). However, a well-timed treatment with AcPepA resulted in decreases in PAP and PVRI, which contributed to the normalizing of LHEDV.

In order to determine the effects of $\mathrm{C} 5 \mathrm{a}$ antagonist treatment, we had to consider and rule out artificial influences which may originate from the experimental design. We therefore applied standard fluid replacement therapy in all groups to exclude the effects of the volume status on the macrohaemodynamic parameters. In this line, the favourable haemodynamic changes might be consequences of the reduced biomarker release (TNF- $\alpha$, histamine and troponin-T) in the post-tamponade phase after AcPepA treatment.

It has been shown that histamine release is induced by a hypoxic condition (Boros 2003) and complement C5a has a direct role in this histamine release from mast cells (El-Lati et al. 1994). An elevated histamine level in the plasma may lead to enhanced vascular permeability and a relative blood loss into the dilated vessels, as can occur in the pulmonary circulation in association with the increase in EVLWI (Walkenstein et al. 1985). On the other hand, the elevation in plasma histamine level in the early post-tamponade phase shows that this level is higher in the portal venous blood than in the arterial blood (Kaszaki et al. 1989). It can decrease the peripheral resistance in patients with circulatory shock (Nagy et al. 1986), while in the splanchnic area histamine release probably plays a role in the counter-regulation of the excessive, prolonged vasoconstriction that contributes to the lethal outcome (Kaszaki et 
al. 1989). In the presence of AcPepA, the extent of histamine release was reduced, and this effect too can contribute to the increased venous return.

There is increasing evidence that cytokines in general and TNF- $\alpha$ in particular play an important role in cardiovascular diseases. Thus, increased levels of TNF- $\alpha$ or of its soluble receptors have been implicated in the pathophysiology of ischaemia-reperfusion injury, myocarditis, and the progression of congestive heart failure. TNF- $\alpha$ modulates the two most important haemodynamic determinants of the cardiac function: the peripheral resistance and the cardiac contractility. As concerns the latter, TNF- $\alpha$ could be responsible for a negative inotropic effect, by altering intracellular $\mathrm{Ca}^{2+}$ homoeostasis and possibly by inducing NO synthesis, which likewise reduces myocyte contractility (Ferrari et al. 1999). An increased expression of TNF- $\alpha$ has been demonstrated in a case where infection of the myocardium with Influenza A virus was associated with cardiac tamponade, as a potentially fatal complication (Mamas et al. 2007). Our experimental data confirm that an acute cardiac tamponade induces TNF- $\alpha$ release directly, whereas the administration of AcPepA significantly limits its release.

Plasma troponin- $\mathrm{T}$ is an indirect, but highly sensitive marker of cardiac tissue ischaemia and has been used to demonstrate the ischaemic effect of a cardiac tamponade (Kelley et al. 2009). The lower level of troponin-T following the relief of the cardiac tamponade in the AcPepA-treated tamponade group could be a multiple result of the inhibition of the complement system.

In conclusion, these results demonstrate the relative significance of complement activation in the acute circulatory complications of a cardiac tamponade, and the potential role of C5a antagonism to reduce inflammatory signals which are important components in the development of disturbances of the LV function and the pulmonary circulation. 


\section{SUMMARY OF NEW FINDINGS}

I. We have used a clinically relevant large animal model to study the haemodynamic and inflammatory changes caused by a cardiac tamponade. A cardiac tamponade induced significant deteriorations of the intestinal macro- and microcirculations, together with impairments of the LV function and pulmonary circulation, associated with potentially harmful inflammatory consequences in the post-tamponade phase.

II. Definite signs of inflammatory activation were observed with the release of vasoactive and pro-inflammatory mediators, including histamine, big-ET, HMGB-1 and the complement system. Influencing these reactions could possibly offer adjuvant therapeutic targets through which to decrease the complications of cardiogenic shock induced by tamponade.

III. Via early therapeutic interventions targeting the inhibition of complement C5a with AcPepA, the secondary detrimental circulatory consequences of the cardiac tamponade can be dampened or reversed. 


\section{REFERENCES}

1. Anrep GV, V Saalfeld E: The effect of the cardiac contraction upon the coronary flow. J Physiol 1933; 79: 317-331.

2. Avontuur JA, Biewenga M, Buijk SL, Kanhai KJ, Bruining HA: Pulmonary hypertension and reduced cardiac output during inhibition of nitric oxide synthesis in human septic shock. Shock 1998; 9: 451-454.

3. Bailey RW, Bulkley GB, Hamilton SR, Morris JB, Haglund UH, Meilahn JE: The fundamental hemodynamic mechanism underlying gastric "stress ulceration" in cardiogenic shock. Ann Surg 1987; 205: 597-612.

4. Bernal JM, Pradhan J, Li T, Tchokonte R, Afonso L: Acute pulmonary edema following pericardiocentesis for cardiac tamponade. Can J Cardiol 2007; 23: 1155-1156.

5. Boda D, Kaszaki J, Tálosi G: A new simple tool for tonometric determination of the $\mathrm{pCO}_{2}$ in the gastrointestinal tract. In vitro and in vivo validation studies. Eur J Anaesthesiol 2006; 23: 680-685.

6. Bodson L, Bouferrache K, Vieillard-Baron A: Cardiac tamponade. Curr Opin Crit Care 2011; 17: 416-424.

7. Bond RF, Green HD: Peripheral circulation. In: Altura BM, Lefer AM, Schumer W (eds): "Handbook of Shock and Trauma." New York: Raven Press, Vol 1, p29, 1983.

8. Boros M, Kaszaki J, Nagy S: Oxygen free radical-induced histamine release during intestinal ischemia-reperfusion. Eur Surg Res 1989; 21: 297-304.

9. Boros M, Massberg S, Baranyi L, Okada H, Messmer K: Endothelin-1 induces leukocyte adhesion in submucosal venules of the rat small intestine. Gastroenterology 1998; 114: 103-114.

10. Boros M: Microcirculatory dysfunction during intestinal ischemia-reperfusion. Acta Physiol Hung 2003; 90: 263-279.

11. Brathwaite CEM, Rodriguez A, Turney SZ, Dunham CM, Cowley RA: Blunt traumatic cardiac rupture. Ann Surg 1990; 212: 701-704.

12. Buerke M, Lemm H, Dietz S, Werdan K: Pathophysiology, diagnosis, and treatment of infarction-related cardiogenic shock. Herz 2011; 36: 73-82. 
13. Bulkley GB, Kvietys PR, Perry MA, Granger DN: Effects of cardiac tamponade on colonic hemodynamics and oxygen uptake. Am J Physiol 1983; 244: G604-G612.

14. Chien S: Role of the sympathetic nervous system in hemorrhage. Physiol Rev 1967; 47: 214-288.

15. De Backer D, Ortiz JA, Salgado D: Coupling microcirculation to systemic hemodynamics. Curr Opin Crit Care 2010; 16: 250-254.

16. El-Lati SG, Dahinden CA, Church MK: Complement peptides C3a-and C5a-induced mediator release from dissociated human skin mast cells. J Investigative Dermatology 1994; 102: 803-806.

17. Eppinger MJ, Deeb GM, Bolling SF, et al.: Mediators of ischemia-reperfusion injury of rat lung. Am J Pathol 1997; 150: 1773-1784.

18. Fazekas L, Kékesi V, Soós P, Barát E, Huszár E, Juhász-Nagy A: Coronary metabolic adaptation restricted by endothelin in the dog heart. Acta Physiol Hung 2001; 88: 35-46.

19. Ferrari R: The role of TNF- $\alpha$ in cardiovascular disease. Pharmacological Research 1999; 40:97-105.

20. Fujita E, Farkas M, Campbell W, Baranyi L, Okada H, Okada N: Inactivation of C5a anaphylatoxin by a peptide that is complementary to a region of C5a. J Immunol 2004; 172: 6382-6387.

21. Girardi G, Berman J, Redecha P, Spruce L, Thurman JM, Kraus D, Hollmann TJ, Casali P, Caroll MC, Wetsel RA, Lambris JD, Holers VM, Salmon JE: Complement C5a receptors and neutrophils mediate fetal injury in the antiphospholipid syndrome. J Clin Invest 2003; 112: 1644-1654.

22. Goldstein JA Cardiac tamponade, constrictive pericarditis, and restrictive cardiomyopathy. Curr Probl Cardiol 2004; 29: 503-567.

23. Gorcsan J, Romand JA, Mandarino WA, Deneault LG, Pinsky MR: Assessment of LV performance by on-line pressure area relations using echocardiographic automated borde definition. J Am Coll Cardiol 1994; 23: 242-252.

24. Gregg DE: Effect of coronary perfusion pressure or coronary flow on oxygen usage of the myocardium. Circ Res 1963; 13: 497-500. 
25. Grumann A, Baretto L, Dugard A, Morera P, Comu E, Amiel JB, Vignon PP: Localized cardiac tamponade after open heart surgery. Ann Thorac Cardiovasc Surg 2012; 18: 524529.

26. Kaszaki J, Czóbel M, Szalay L, Nagy S, Boros M: Endothelin-1 induces organ-specific histamine liberation and neutrophil granulocyte accumulation in the rat. Inflamm Res 2008; 57: 396-402.

27. Kaszaki J, Nagy S, Tárnoky K, Laczi F, Vecsernyés M, Boros M: Humoral changes in shock-induced by cardiac-tamponade. Circ Shock 1989; 29: 143-153.

28. Kelley WE, Januzzi JL, Christenson RH: Increases of cardiac troponin in conditions other than acute coronary syndrome and heart failure. Clinical Chemistry 2009; 55: 2098-2112.

29. Klopfenstein HS, Bernath GA, Cogswell TL, Boerboom LE: Coronary artery hemodynamics in conscious dog during cardiac tamponade. Circ Res 1987; 60: 845-849.

30. Kolkman JJ, Otte JA, Groeneveld AB: Gastrointestinal luminal $\mathrm{pCO}_{2}$ tonometry: an update on physiology, methodology and clinical applications. Br J Anaesth 2000; 84: 7486.

31. Kuebler WM, Abels C, Schuerer L, Goetz AE: Measurement of neutrophil content in brain and lung tissue by a modified myeloperoxidase assay. Int $\mathbf{J}$ Microcirc Clin Exp 1996; 16: 89-97.

32. Ligero C, Leta R, Bayes-Genis A: Transient biventricular dysfunction following pericardiocentesis. Eur J Heart Failure 2006; 8: 102-104.

33. Loomis ED, Sullivan JC, Osmond DA, Pollock DM, Pollock JS: Endothelin mediates superoxide production and vasoconstriction through activation of NADPH oxidase and uncoupled nitric-oxide synthase in the rat aorta. J Pharmacol Exp Ther 2005; 315: 10581064.

34. Mamas MA, Nair S Fraser D: Cardiac tamponade and heart failure as a presentation of influenza. Exp Clin Cardiol. 2007; 12: 214-216.

35. Mitiku TY, Heidenreich PA: A small pericardial effusion is a marker of increased mortality. Am Heart J 2011; 161: 152-157.

36. Molnár G, Csonka E, Vass A, Boros M, Kaszaki J: Circulatory consequences of reduced endogenous nitric oxide production during small-volume resuscitation. Acta Physiol Hung 2011; 98: 393-408. 
37. Moshage H, Kok B, Huizenga JR, Jansen PL: Nitrite and nitrate determinations in plasma: a critical evaluation. Clin Chem 1995; 41: 892-896.

38. Nagy S, Nagy A, Adamicza A, Szabó I, Tárnoky K, Traub A: Histamine level changes in the plasma and tissues in hemorrhagic shock. Circ Shock 1986; 18: 227-239.

39. Odenstedt H, Aneman A, Svensson YOM, Stenqvist O, Lundin S: Descending aortic blood flow and cardiac output: a clinical and experimental study of continuous oesophageal echo-Doppler flowmetry. Acta Anaesthesiol Scand 2001; 45: 180-187.

40. Okada H, Imai M, Ono F, et al: Novel complementary peptides to target molecules. Anticancer Res 2011; 31: 2511-2516.

41. Okada N, Asa S, Hotta A, et al. Increased inhibitory capacity of an anti-C5a complementary peptide following acetylation of $\mathrm{N}$-terminal alanine. Microbiology and Immunology 2007; 51: 439-443.

42. Park M, Maciel AT, Noritomi DT, Brunialti MK, Salomão R, Schettino GPP, Azevedo LCP: Is persistent hypotension after transient cardiogenic shock associated with an inflammatory response? Braz J Med Biol Res 2008; 41: 648-656.

43. Parrillo JE Shock (in: Harrison's Principles of Internal Medicine $12^{\text {th }}$ edition, ed.: Wilson JD, Mc Grow-Hill Inc., New York 1991. pp:232-236.

44. Phillips CP, Vinecore K, Hagg DS, Sawai RS, Differding JA, Watters JM, Schreiber MA: Resuscitation of hemorrhagic shock with normal saline vs. lactated Ringer's: effects on oxygenation, extravascular lung water and hemodynamics. Critical Care 2009; 13: R30-

45. Prasad K, Kalra J, Chaudhary AK, Debnath D: Polymorphonuclear leukocyte activation and cardiac function at organ and cellular level. Am Heart J 1990; 119: 538-550.

46. Reuter DA, Huang C, Edrich T, et al: Cardiac output monitoring using indicator-dilution techniques: Basics, limits, and perspectives. Anesth Analg 2010; 110: 799-811.

47. Sarma JV, Ward PA: The Complement System. Cell Tissue Res 2011; 343: 227-235.

48. Scaffidi P, Misteli T, Bianchi ME: Release of chromatin protein HMGB1 by necrotic cells triggers inflammation. Nature 2002; 418: 191-195.

49. Seferovic PM, Ristic AD, Imazio M, Maksimović R, Simeunović D, Trinchero R, Pankuweit S, Maisch B: Management strategies in pericardial emergencies. Herz 2006; 31: 891-900. 
50. Sheehy AM, Burson MA, Black SM: Nitric oxide exposure inhibits endothelial NOS activity but not gene expression: a role for superoxide. Am J Physiol 1998; 274: L833L841.

51. Skalidis EI, Kochiadakis GE, Chrysostomakis SI, Igoumenidis NE, Manios EG, Vardas PE: Effect of pericardial pressure on human coronary circulation. Chest 2000; 117: 910912.

52. Soop A, Albert J, Weitzberg E, Bengtsson A, Lundberg JO, Sollevi A: Complement activation, endothelin-1 and neuropeptide $\mathrm{Y}$ in relation to the cardiovascular response to endotoxin-induced systemic inflammation in healthy volunteers. Acta Anaesthesiol Scand 2004; 48: 74-81.

53. Topalian S, Ginsberg F, Parrillo JE: Cardiogenic shock. Crit Care Med 2008; 36: S66S74.

54. Trepte CJC, Eichhorn V, Haas SA, Richter HP, Goepfert MS, Kubitz JC, Goetz AE, Reuter DA: Thermodilution-derived indices for assessment of left and right ventricular cardiac function in normal and impaired cardiac function. Crit Care Med 2011; 39: 21062112.

55. Tyson GS, Maier GW, Olsen CO, Dawis JW, Rankin JS: Pericardial influences on ventricular filling in the conscious dog. Circ Res 1984; 54: 173-184.

56. Ulloa L, Messmer D: High-mobility group box 1 HMGB1; protein: friend and foe. Cytokine Growth Factor Rev 2006; 17: 189-201.

57. Valley VT, Fly CA: Pericarditis and Cardiac Tamponade (rewiev) www.emedicine.com/emerg/topic 412.htm 2007.

58. Végh T, Bérczy K, Juhász M, Sira G, Balogh L, Veres L, Fülesdi B: The use of pulse contour cardiac output-volumetric ejection fraction monitoring system in thoracic anaesthesia for high-risk patient: case report. Eur J Anaesthesiol 2009; 26: 1085-1088.

59. Walkenstein MD, Peterson BT, Gerber JE, Hyde RW: Histamine-induced pulmonary edema distal to pulmonary arterial occlusion. J Appl Physiol 1985; 58: 1092-1098.

60. Ward PA: Sepsis, apoptosis and complement. Biochem Pharmacol 2008; 76: 1383-1388.

61. Wolfárd A, Szalay L, Kaszaki J, Sahin-Tóth G., Vangel R., Balogh Á., Boros M.: Dynamic in vivo observation of villius microcirculation during small bowel 
autotransplantation: effects of endothelin-A receptor inhibition. Transplantation 2002; 73: 1511-1514.

62. Wolfard A, Vangel R, Szalay L, Kaszaki J, Haulik L, Balogh Á, Nagy S, Boros M: Endothelin-A receptor antagonism improves small bowel graft perfusion and structure after ischemia and reperfusion. Transplantation 1999; 68: 1231-1238.

63. Yang H, Wang H, Czura CJ, Tracey KJ: HMGB1 as a cytokine and therapeutic target. J Endotoxin Res 2002; 8: 469-472.

64. Zimmermann T, Schuster R, Lauschke G, Trausch M: Chemiluminescence response of whole-blood and separated blood-cells in cases of experimentally induced pancreatitis and mdtq-da trasylol ascorbic-acid therapy. Anal Chimica Acta 1991; 255: 373-381. 


\section{ACKNOWLEDGEMENTS}

I would like to express my gratitude to Professor Mihály Boros, head of the Institute of Surgical Research, for his scientific guidance. I deeply appreciate his constant support through the years during which I have had the possibility to work in the institute.

I owe my gratitude to Professor Tamás Forster, head of the Second Department of Medicine and Cardiology Centre, for his inspiration and support of my experimental and scientific work.

I am especially grateful to my supervisor, Dr. József Kaszaki, for his personal guidance and for introducing me to experimental surgery. Without his continuous encouragement, never-failing interest, and optimistic attitude to the scientific problems, this Ph.D. study might never have been completed.

I would like to express my deepest appreciation to Professor Miklós Csanády, former head of the Second Department of Medicine and Cardiology Centre, for admitting me to the Echocardiography Team of the department as a young physician, and to Dr. Mátyás Sereg, former head of the Cardiology Department at Szent-György Hospital, who introduced me to cardiology.

My special thanks are due to all the technical staff at the Institute of Surgical Research and the nurses of the echocardiography laboratory in the Second Department of Medicine and Cardiology Centre. Their skilful activities and enthusiastic work have helped me overcome many difficulties and have greatly facilitated the experiments and the clinical studies.

Last but not least, I would like to express my never-ending gratitude to my family, who were always with me.

This study was supported by research grants OTKA K104656, TÁMOP-4.2.2.A11/1/KONV-2012-0035 and TÉT JP 16/09. 


\section{ANNEX}

1. Érces D, Nógrády M, Nagy E, Varga G, Vass A, Süveges G, Imai M, Okada N, Okada H, Boros M, Kaszaki J: Complement c5a antagonist treatment improves the acute circulatory and inflammatory consequences of experimental cardiac tamponade. Crit Care Med 41: 2013. (accepted for publication) DOI: 10.1097/CCM.0b013e31828a6768

2. Vass A, Süveges G, Érces D, Nógrády M, Varga G, Földesi I, Futakuchi M, Imai M, Okada N, Okada H, Boros M, Kaszaki J: Inflammatory activation after experimental cardiac tamponade. Eur Surg Res 51:1-13, 2013. DOI: 10.1159/000352089

3. Molnár G, Csonka E, Vass A, Boros M, Kaszaki J: Circulatory consequences of reduced endogenous nitric oxide production during small-volume resuscitation. Acta Physiol Hung 98: 393-408, 2011. 